\title{
Should the Randomistas (Continue to) Rule?
}

\section{Martin Ravallion}

\begin{abstract}
The rising popularity of randomized controlled trials (RCTs) in development applications has come with continuing debates about the merits of this approach. The paper takes stock of the issues. While RCTs have an important place in the toolkit for impact evaluation, an unconditional preference for RCTs as the "gold standard" is questionable on three main counts. First, the case for such a preference is unclear on a priori grounds; indeed, for a given budget, even a biased observational study may well come closer to the truth than an RCT. Second, the ethical objections to RCTs call for a stronger defense than is commonly found at present. Third, there is a serious risk of distorting the evidence-base for informing development policymaking, given that an insistence on doing RCTs generates selection bias in what gets evaluated. Going forward, pressing knowledge gaps should drive the questions asked and how they are answered, not the methodological preferences of some researchers. The gold standard is the best method for the question at hand.
\end{abstract}

Keywords: Randomized controlled trials; bias; ethics; external validity; development policy

JEL: B23, H43, O22

* This paper was first published in August 2018. It was updated in January 2019. You can view the previous version of the paper here: https://www.cgdev.org/sites/default/files/should-randomistascontinue-rule.pdf 


\title{
Should the Randomistas (Continue to) Rule?
}

\author{
Martin Ravallion \\ Department of Economics, Georgetown University
}

François Roubaud encouraged the author to write this paper. The author thanks Jason Abaluck, Sarah Baird, Mary Ann Bronson, Caitlin Brown, Sylvain Chabé-Ferret, Kevin Donovan, Markus Goldstein, Miguel Hernan, Emmanuel Jimenez, Max Kasy, Madhulika Khanna, Nishtha Kochhar, Andrew Leigh, David McKenzie, Rachael Meager, Berk Özler, Dina Pomeranz, Lant Pritchett, Milan Thomas, Vinod Thomas, Eva Vivalt, Dominique van de Walle, Andrew Zeitlin and staff of the International Initiative for Impact Evaluation, who kindly provided an update to their database on published impact evaluations and helped with the author's questions.

Martin Ravallion, 2018. "Should the Randomistas (Continue to) Rule?.” CGD Working Paper 492. Washington, DC: Center for Global Development. https://www.cgdev.org/ publication/should-randomistas-continue-rule

Center for Global Development 2055 L Street NW Washington, DC 20036

202.416.4000

(f) 202.416 .4050

www.cgdev.org
The Center for Global Development works to reduce global poverty and improve lives through innovative economic research that drives better policy and practice by the world's top decision makers. Use and dissemination of this Working Paper is encouraged; however, reproduced copies may not be used for commercial purposes. Further usage is permitted under the terms of the Creative Commons License.

The views expressed in CGD Working Papers are those of the authors and should not be attributed to the board of directors, funders of the Center for Global Development, or the authors' respective organizations. 


\section{Contents}

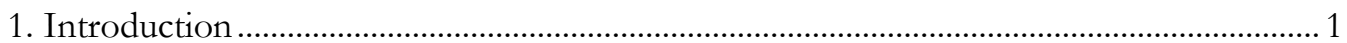

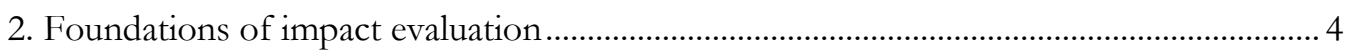

3. The influence of the randomistas on development research ..............................................10

Why have the randomistas had so much influence? ........................................................11

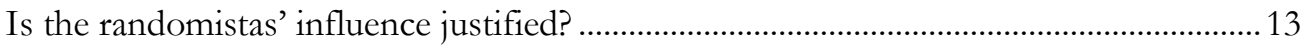

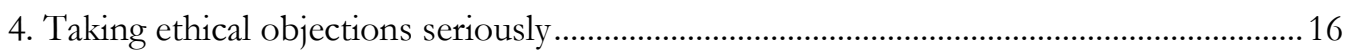

5. Relevance to policymaking .............................................................................................. 19

Policy-relevant parameters: ...............................................................................................2 20

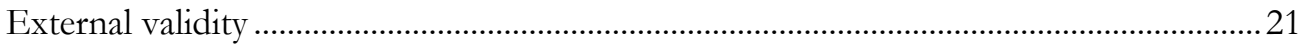

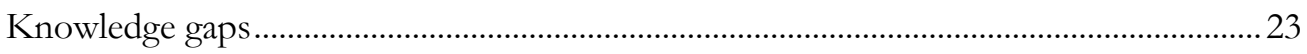

Matching research efforts with policy challenges ............................................................ 24

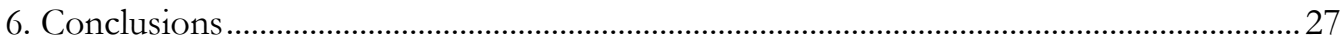

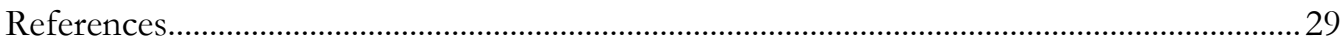




\section{Introduction}

Impact evaluations (IEs) can provide useful support for evidence-based policymaking. There are two broad groups of methods. In the first, access to a program (the "treatment") is randomly assigned to some units, with others randomly set aside as controls. To measure the program's impact one then compares mean outcomes for these two samples. This is a randomized controlled trial (RCT). The second group comprises purely "observational studies" (OSs) in which the assignment of treatment status is purposive rather than random. While some OSs are purely descriptive, others attempt to control for the pre-treatment differences between treated and un-treated units based on what can be observed in data, with the aim of making causal inferences about the impact.

The new millennium has seen a huge increase in the application of IEs to developing countries. The International Initiative for Impact Evaluation (3ie) has compiled metadata on such evaluations. ${ }^{1}$ Their data indicate a remarkable 30 -fold increase in the annual production of published IEs since 2000, compared to the 19 years prior to $2000 .{ }^{2}$ Figure 1 gives the 3ie series for both groups of methods, 1988-2015. The counts for both have grown rapidly since $2000 .^{3}$ This growth in IEs holds promise for better policymaking.

About $60 \%$ of the IEs since 2000 have used randomization. The latest 3ie count has 333 papers using this tool for $2015 .{ }^{4}$ The growth rate is striking. Fitting an exponential trend (and the fit is good) to the counts of RCTs in Figure 1 yields an annual growth rate of around $20 \%$-more than double the growth rate for all scientific publishing post-WW2. ${ }^{5}$ As a further indication, if one enters "RCT" or "randomized controlled trial" in the Google Ngram Viewer one finds that the incidence of these words (as a share of all ngrams in digitized text) has tended to rise over time and is higher at the end of the available time series (2008) than ever before.

\footnotetext{
1 See Cameron et al. (2016) and Sabet and Brown (2018). The numbers here are from an updated database spanning 1981-2015.

2 4,501 IEs are recorded in the 3ie database, covering the period 1981-2015, of which 4,338 were published in 2000-15. The annual rates are 271 since 2000 and 9 for 1981-1999.

3 The 3 ie series is constructed by searching for selected keywords in digitized texts. 3ie staff warned me (in correspondence) that their old search protocols were probably less effective in picking up OSs relative to RCTs prior to 2000. So the earlier, lower, counts of non-randomized IEs in Figure 1 may be deceptive.

4 To put this in perspective for economists, this is about the same as the total number of papers (in all fields) published per year in the American Economic Review, Journal of Political Economy, Quarterly Journal of Economics, Econometrica and the Review of Economic Studies (Card and DellaVigna, 2013).

5 Regressing log RCT count (dropping three zeros in the 1980s) on time gives a coefficient of 0.20 (s.e. $=0.01$; $\left.\mathrm{n}=32 ; \mathrm{R}^{2}=0.96\right)$ or $0.18\left(0.01 ; \mathrm{n}=16 ; \mathrm{R}^{2}=0.96\right)$ if one only uses the series from 2000 onwards. In modern times (post-WW2), the growth rate of scientific publications is estimated to be $8-9 \%$ per annum (Bornmann and Mutz, 2015).
} 
Figure 1: Annual counts of published impact evaluations for developing countries

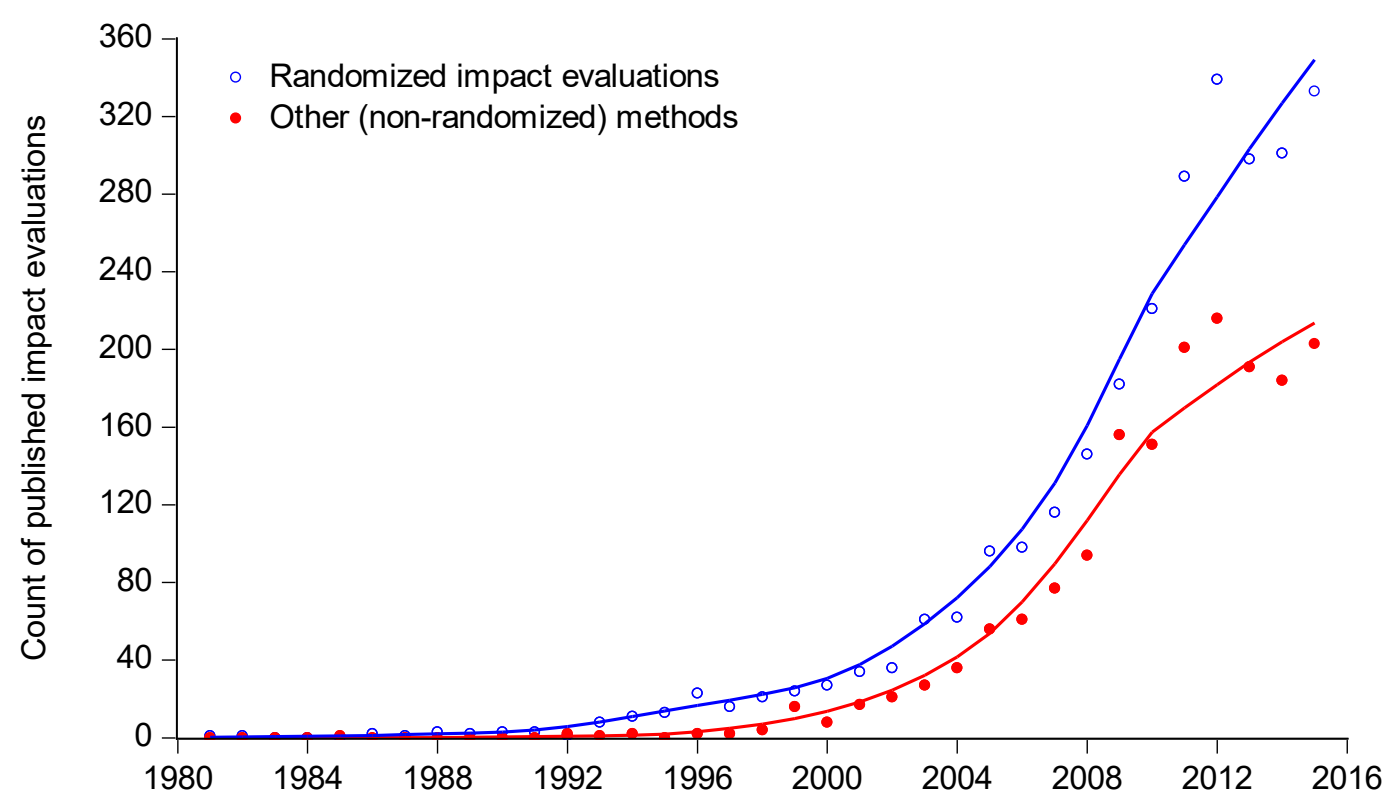

Note: Fitted lines are nearest neighbor smoothed scatter plots. See footnote 4 in the main text on likely undercounting of non-randomized IEs in earlier years. Source: International Initiative for Impact Evaluation.

The fact that so much of the growth evident in Figure 1 has been for RCTs would surely not have been anticipated prior to 2000. After all, RCTs are not feasible for many of the things that governments and others do in the name of development. Nor had RCTs been historically popular, given the often-heard concerns about withholding a program from some people who need it, while providing it to some who do not, for the purpose of research. Development RCTs used to be a hard sell. Something changed. How did RCTs become so popular? And is their popularity justified?

Advocates of RCTs have been dubbed the "randomistas." 6 They proffer RCTs as the "gold standard" for impact evaluation-the most "scientific" or "rigorous" approach, promising to deliver largely atheoretical and assumption-free, yet reliable, IE. ${ }^{7}$ This view has come from prominent academic economists, and it has permeated the popular discourse, with discernable influence in the media, development agencies and donors, as well as among researchers and their employers. ${ }^{8}$ This is an unconditional preference for RCTs. While there

\footnotetext{
6 That term "randomistas" is not pejorative; indeed, RCT advocates also use it approvingly, such as Leigh (2018).

7 For example, Banerjee (2006) writes that: "Randomized trials like these - that is, trials in which the intervention is assigned randomly — are the simplest and best way of assessing the impact of a program." Similarly, Imbens (2010, p.407) claims that "Randomized experiments do occupy a special place in the hierarchy of evidence, namely at the very top." And Duflo (2017, p.3) refers to RCTs the "tool of choice." Pritchett (2018, p.20) criticizes RCTs on a number of counts but still agrees that the tool "is superior to other evaluation methods." 8 An example of the broader influence of the "gold standard" view is the Wikipedia entry on IE, which states that "Randomized field experiments are the strongest research designs for assessing program impact... as it allows for a fair and accurate estimate of the program's actual effects.” In another example, Keating (2014) writes
} 
are a great many contexts for an IE (types of interventions, sectors of the economy, countries, communities, social/ethnic groups), the gold-standard claim is typically made independently of context.

There has been a pushback too. RCTs in social-policy applications have raised many concerns. ${ }^{9}$ Critics have argued that (inter alia): the assumptions required for a reliable impact estimate using an RCT need not hold in reality; RCTs are ethically questionable; and the "black box" nature of RCTs limits their usefulness for policymaking, including both scaling up and learning about likely impact in other contexts. There have been defenses against the critics. ${ }^{10}$

In the light of the rising prominence of development RCTs, and the continuing debates, this paper returns, 10 years later, to the question posed in Ravallion (2009a), "Should the randomistas rule?"11 The sense in which randomistas "rule" is in their claimed hierarchy of methods, which is the foundation of their intellectual authority and power to persuade. ${ }^{12}$ That hierarchy is the main focus of the paper. While acknowledging the attractions of RCTs for some purposes, the paper argues that the supportive public narrative on RCTs that has emerged is not well grounded in an appreciation of the limitations of this research tool. The paper's intended audience is not the experts on either side, but the broader community of economists and other social scientists, donors, policymakers and their advisors, students and young researchers.

The paper begins with an overview of the theory of impact evaluation, as relevant to the choice of methods (Section 2). It then discusses the randomistas' influence on development research (Section 3), the concerns about the ethical validity of their preferred method (Section 4), and the relevance of their research to policy (Section 5). Section 6 concludes.

that "Randomistas, proponents of randomized controlled trials, have recently been transforming the way we think about economic development and aid to poor countries." Similarly, Leigh's (2018) volume is entitled "Randomistas: How Radical Researchers Changed our World."

9 See Heckman and Smith (1995), Grossman and Mackenzie (2005), Cartwright (2007), Ravallion (2009a,b; 2012), Rodrik (2009), Barrett and Carter (2010), Deaton (2010), Keane (2010), Baele (2013), Basu (2014), Mulligan (2014), Pritchett and Sandefur (2015), Favereau (2016), Ziliak and Teather-Posadas (2016), Hammer (2017), Deaton and Cartwright (2018), Pritchett (2018) and Young (2018).

10 Including Banerjee and Duflo (2009), Goldberg (2014), Imbens (2010, 2018), Glennerster and Powers (2016) and McKenzie (2019).

11 This is a substantial update and extension to Ravallion (2009a), also drawing on Ravallion (2016, Chapter 6).

12 Thus, McKenzie's (2019) observation that only 10\% of all papers in development economics (any field, in 14 journals) are RCTs does not refute the claim that the randomistas do indeed rule in the sense used here. 


\section{Foundations of impact evaluation}

An impact evaluation can be thought of as an experimental trial to see how well something works. ${ }^{13}$ The focus is on assigned programs, in that some units (the "treated") in a welldefined population get the program and some do not.

Imagine drawing two random samples from the population, one from those treated and one from those not, and then measuring relevant outcomes for both. This constitutes a single trial. The difference in mean outcomes is the trial's estimate of the true mean impact for that population, also called the average treatment effect (ATE). That estimate can differ from the true value due to measurement errors, sampling variability, spillover effects ("contamination") between the two groups, monitoring effects, and systematic bias due to any confounding variables that jointly alter outcomes and treatment status. Each trial's sampled pair gives a different estimate, sometimes too high, sometimes too low, though we never know by how much since we do not (of course) know the true value. Every trial result has some experimental error.

The ideal RCT is the special case in which the trial's treatment status is also chosen randomly (in addition to drawing random samples from the two populations, one treated and one not) and the only error is due to sampling variability. In this special case, as the sample sizes increase, the trial's estimate gets closer to the true mean impact. This is the sense in which an ideal RCT is said to be unbiased, namely that the sampling error is driven to zero in expectation. This property also allows us to estimate the variance of the estimates from RCTs. Thus, using both random assignment and random sampling facilitates calculation of the standard error of the impact estimate, to establish a statistical confidence interval. ${ }^{14}$

Prominent randomistas have sometimes left out the "in expectation" qualifier, or ignored its implications for the existence of experimental errors (Deaton and Cartwright, 2018). They attribute any difference in mean outcomes between the treatment and control samples to the intervention. ${ }^{15}$ This common mistake might be thought of as little more than a minor

\footnotetext{
${ }^{13}$ In the literature, the word "experiment" is sometimes defined as any situation in which the evaluator controls everything, and this is deemed to be the case for an RCT; see, for example, Cox and Reid (2000). However, it is almost never the case that the evaluator controls everything in RCTs with human subjects, as used to evaluate social policies. Here I use the broader definition of "experiment" as a trial, not assuming full control. It may be an RCT or an OS.

${ }^{14}$ Current practices in this respect can be questioned. Young (2018) points to a number of concerns in past impact estimates of standard errors when using RCTs with regression controls and shows that many published economics papers have over-estimated the statistical significance of their impact estimates. This depends in part on whether one is interested in testing the null that mean impact is zero or that impact is zero for every treated unit, which is (of course) more demanding. Also see the discussions in Deaton and Cartwright (2018) and Imbens (2018).

${ }^{15}$ For example, with reference to RCTs, Banerjee and Duflo (2017) write that "any difference between the treatment group and the comparison group can be confidently attributed to the treatment," and Banerjee et al. (2019) claim that an RCT ensures that "any difference between treatment and control units reflects the impact of the treatment." One finds a similarly unguarded claim in the "Introduction to Evaluation" on the website of the
} 
expository simplification. ${ }^{16}$ However, the simplification is now embedded in much of the public narrative. Beyond the experts (putting aside their unguarded statements), many people in the development community now think that any measured difference between the treatment and control groups in an RCT is attributable to the treatment. It is not; even the ideal RCT has some unknown error.

A rare but instructive case is when there is no treatment. Absent any other effects of assignment (such as from monitoring), the impact is zero. Yet the random experimental error can still yield a non-zero mean impact from an RCT. An example is an RCT in Denmark in which 860 elderly people were randomly and unknowingly divided into treatment and control groups prior to an 18-month period without any actual intervention (Vass, 2010). A statistically significant (prob. $=0.003$ ) difference in mortality rates emerged at the end of the period.

In the light of these observations, consider the choice of methods. Suppose that, with a given budget, we can implement either an RCT or an OS. For the latter, people are free to select into the program, and we take random samples of those who do and those that do not. We want to rank the methods $e x$ ante according to how close their trial estimates are likely to be to the true value. Let us say that an estimate is "close to the truth" if it is within some fixed interval centered on the true value. (The focus here is on the "internal validity" of each estimator-its accuracy for the population in hand; Section 5 turns to "external validity.")

The reason one hears most often for the "gold-standard" ranking is the unbiasedness of an ideal RCT. Economists have focused a lot on one particular source of bias, namely any difference between the mathematical expectation of a parameter estimate and its (unknown) true value. (In some of the literature this is called "systematic bias," as distinct from the, potentially many, sources of trial-specific errors. ${ }^{17}$ ) Even by this narrow definition, an OS need not be biased. One typically adjusts for covariate imbalance, whether an RCT or OS. Bias in an OS is removed if the treatment is conditionally exogenous, i.e., uncorrelated with the error term conditional on the covariates, though this is clearly a stronger assumption than for an RCT. That assumption may or may not be acceptable, depending on the context (the program and the data available). Whether or not the treatment is exogeneous given the control variables depends on whether those variables adequately reflect the determinants of treatment placement; that must be judged in each setting. Omitted confounders will often remain, although that does not mean large biases on adjusting for the observed confounders.

\footnotetext{
Abdul Latif Jameel Poverty Action Lab (J-PAL) (which Section 3 returns to); having described a stylized RCT for a water purification project, with treatment and control groups, J-PAL says that: "any differences seen later on can be attributed to one having been given the water purification program, and the other not." Another example is found in a technical manual on IE by the Inter-American Development Bank and the World Bank (Gertler et al. 2016).

16 As Imbens (2018) suggests, in his comments on Deaton and Cartwright (2018).

17 There is a good discussion of the multiple sources of bias in Hernan and Robins (2018).
} 
If unmeasured confounders are a serious concern then the bias can be removed if one has a valid instrumental variable (IV). This must be correlated with treatment status and uncorrelated with outcomes, given treatment and control variables. In a regression, this requires that the IV is uncorrelated with the error term—giving what is called the "exclusion restriction." This must be judged on theoretical grounds. For example, consider a program for which the assignment to treatment depends on whether an eligibility score is above some critical threshold, along with other factors, adding fuzziness to the assignment. As long as the threshold is arbitrary (namely that mean counterfactual outcomes do not change at the threshold), whether the score is above or below this critical value is a theoretically defensible IV. ${ }^{18}$ Though less familiar to economists, the theory of causal inference also tells us that bias in an OS due to unmeasured confounders can be eliminated if there is an intermediate variable that links treatment to outcomes but does not depend on the confounders. ${ }^{19}$ The arguments made to justify an OS - the choice of control variables or IVs - constitute what is often called the "identification strategy," and the validity of those arguments is key to the extent of bias in the resulting impact estimates.

Even if we agree that an RCT is better at removing bias in a specific setting, that still does not clinch the ranking. There are two main reasons. First, given the constraints faced on RCTs in practice, it may not be feasible to properly represent the population of interest. At least when there is a free media, governments are likely to see a political risk in supporting ethically-questionable research. While RCTs are sometimes done with governments, more benign OSs are often easier to accept. Academic randomistas looking for local partners undoubtedly see the attractions of working instead with local non-governmental organizations (NGOs). The desire to randomize may thus deliver (under ideal conditions) an unbiased impact estimate for a non-randomly-selected sub-population, such as those in the catchment area of a cooperative local NGO. Furthermore, the selection process for that subsample may be far from clear, even based on observables. Given the likely heterogeneity in impacts, the (biased) OS may then be closer to the truth for the whole population.

Second, bias is not the only thing that matters. Indeed, it has long been recognized that unbiased estimators can perform poorly in practice. The appropriate decision rule for choosing an estimator (and designing a research study more generally) can depend on the application. ${ }^{20} \mathrm{~A}$ reasonable decision rule for many settings is to minimize the mean-squared error (MSE), i.e., the expected value of the squared deviation between the estimate and its

\footnotetext{
${ }^{18}$ This is an example of regression-discontinuity design; for a formal treatment see Hahn et al. (2001).

${ }_{19}$ This is different to an IV, since the intermediate variable is endogenous. For an example, see Glynn and Kashin (2018). Pearl and Mackenzie (2018, Chapters 4 and 7) provide a non-technical exposition of the difference between "front-door" and "back-door" adjustment. For a more formal treatment see Pearl (2009, Chapter 3).

${ }^{20}$ For example, when calibrating a Proxy Means Test for deciding who is "poor" based on observed but partial indicators of consumption or income, the common practice is to use a regression that minimizes the sum of squared errors in predicting consumption or income. Arguably, a better decision rule in that context is to choose the parameters to minimize a poverty measure subject to budget and informational constraints (Brown et al., 2018).
} 
true value. As is well-known in statistics, the MSE is the estimator's squared bias plus its variance. ${ }^{21}$ Thus, this decision rule does not tell us that an unbiased estimator is necessarily best. ${ }^{22}$ To see why, suppose that each trial is drawn from one of two normal distributions, one for an RCT and one for an OS. The parameters (its mean and variance) depend on the chosen method. The mean of the RCT distribution is taken to be the true mean, while it is not for the OS. Even so, despite the bias, the variance of the OS estimate could be low enough to assure that it yields a higher share of its trials that are close to the truth-a lower MSE. RCTs may end up further from the truth.

The economics of impact evaluation comes into play. Larger sample sizes reduce the variance of estimates. Many OSs use existing data, from administrative records ("big-data"), as well as existing surveys. RCTs have sometimes used administrative data but more often require new special-purpose surveys, especially when outcome variables relate to household welfare. Thus, for a given budget, RCTs will often have lower sample sizes and (hence) higher variances.

Nor is the outcome clear when an OS requires new surveys. A good way to reduce OS bias is with better data. Longer survey questionnaires will probably entail smaller sample sizes.

But the data requirements for an RCT are unlikely to be different, noting that one still needs baseline data to test for covariate balance in an RCT. ${ }^{23}$ The additional randomization (for treatment) in an RCT is unlikely to be costless, and re-randomization may well be needed to assure covariate balance (Morgan and Rubin, 2012). In medical applications, RCTs are widely thought to be more costly than OSs. ${ }^{24}$ I have not seen systematic cost data for development IEs, though one often hears concerns about underpowered RCTs. ${ }^{25}$ Cost comparisons for IEs at the World Bank suggest higher costs for RCTs (though the comparisons are crude). ${ }^{26}$ Development RCTs often encounter difficulties of implementation in the field that are not found for OSs.

${ }^{21}$ If $\beta$ is the true value and $\hat{\beta}$ its estimator then $\operatorname{MSE} \equiv E\left((\hat{\beta}-\beta)^{2}\right)=(E(\hat{\beta})-\beta)^{2}+E\left((\hat{\beta}-E(\hat{\beta}))^{2}\right)$. The first term on the RHS is the squared bias of $\hat{\beta}$ while the second term is its variance.

${ }^{22}$ This is well recognized in introductory econometrics texts. For example, Johnstone (1984, p.28) writes that

“...on the mean-squared-error criterion a biased estimator may be preferred to one with smaller or zero bias if its variance is sufficiently small to offset the larger bias.” Also see the discussion in Greene (1991, pp.97-99). But this point seems to be often forgotten by the randomistas.

${ }^{23}$ Expost balancing tests and retrospective adjustments are often recommended for RCTs (Cox and Reid, 2000; Hinkelmann and Kempthorne, 2008; Bruhn and McKenzie, 2009; Hernán and Robins, 2018).

24 See, for example, Hannan (2008) and Frieden (2017).

${ }^{25}$ For example, in reference to development RCTs, White (2014) says that "..the actual power of many RCTs is only around 50 per cent. So, an RCT is no better than tossing a coin for correctly finding out if an intervention works." Sampling variability appears to account for half or more of the variability in impact estimates from RCTs; see Meager (2018), with reference to microcredit schemes.

26 The World Bank's IEs in recent times have tended to be RCTs with considerably higher average cost than the IEs done in the International Financial Cooperation (within the World Bank Group), where observational studies are more common (World Bank, 2012). This is at best suggestive since the comparison is not properly controlled. 
Figure 2 illustrates a hypothetical case, showing that even a biased OS can be closer to the truth than an (unbiased) RCT. ${ }^{27}$ Two densities are shown for impact estimates from both RCT and OS designs, both drawn from normal distributions. (The densities may or may not be conditional on covariates.) The true impact is zero, which is the mean of the distribution from which the RCT trials are drawn. The OS trials are drawn instead from a distribution with a mean of -0.5 , which is their systematic bias. The other difference is that the RCT trials are drawn from a distribution with a variance of 2 , while for the OS it is 1 . This can be interpreted as saying that, for a given budget, the OS method allows double the sample size in each trial.

Which method does better, in that its trial estimates are closer to the truth? Define "closer to the truth" as being more likely to be within a fixed interval centered on the true value-in this case, an interval $(-\delta, \delta)$ (for some $\delta>0$ ). Figure 3 gives the percentage of trials close to the truth for each method. Suppose we define "closer to the truth" as an impact estimate in the interval $(-0.5,0.5)$. We find that the RCT gets an estimate that is within this interval for $27 \%$ of its trials, but this is so for $34 \%$ of the OS trials. The lower variance of the OS lets it get closer to the truth more often, despite its bias. If instead we define "closer to the truth" as an estimate in the interval $(-1,1)$ then this is so for $52 \%$ of RCT trials versus $62 \%$ using the OS. In this example, the OS is closer to the truth for all $\delta$ !

\section{Figure 2: Density functions for the estimates of mean impact from two hypothetical designs for impact evaluations}

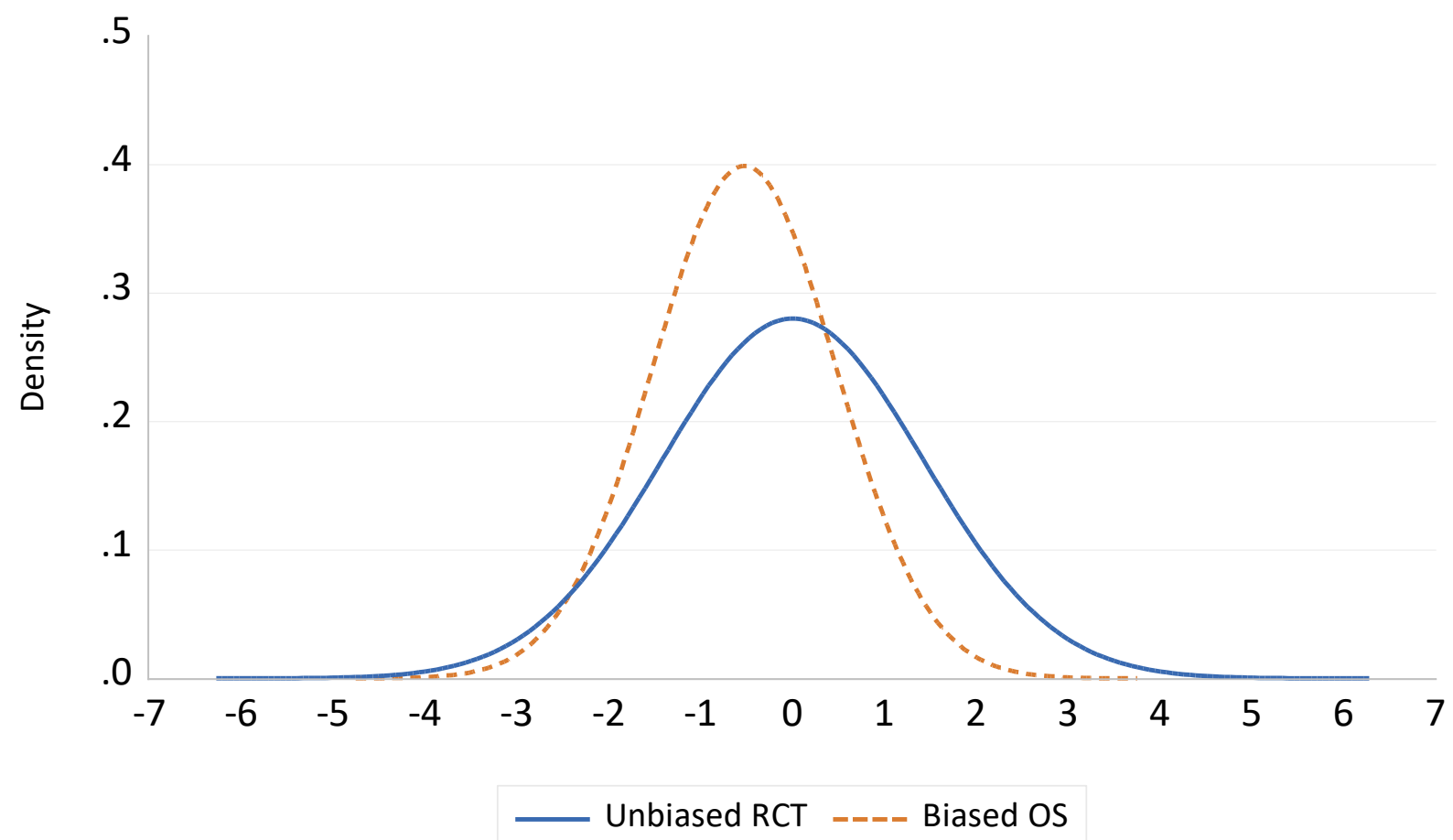

${ }^{27}$ Greene (1991, Section 4 .3) uses a similar example to show that a more biased estimator can have lower MSE. 
Figure 3: Proportion of trials giving an impact estimate that is close to the truth, comparing an unbiased RCT with a biased OS on a larger sample

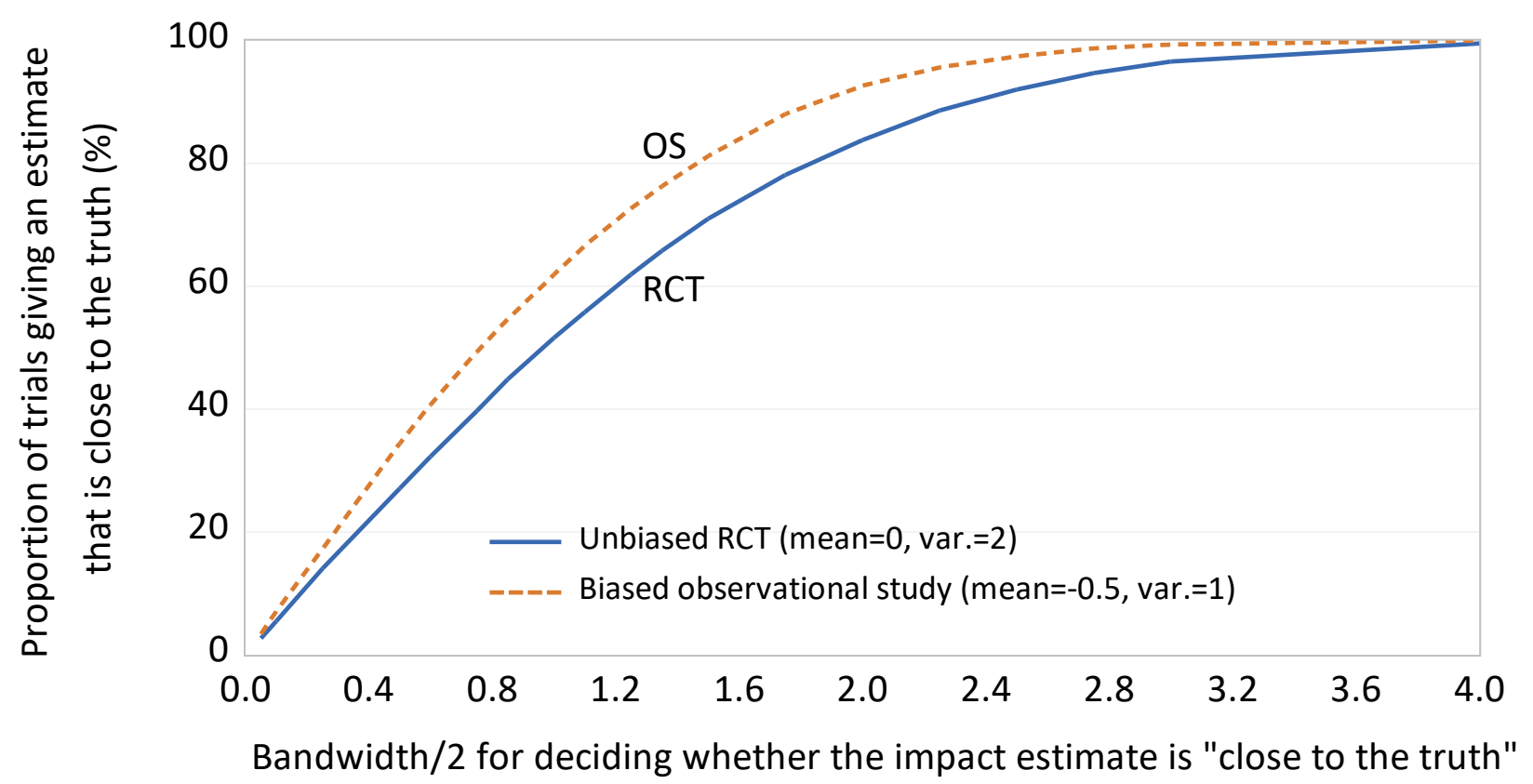

Of course, this is only one of many possibilities, and one can readily construct examples where the RCT does better. Figures 2 and 3 only illustrate that the less biased IE need not get us closer to the truth. That is an open question as it depends crucially on the power of the trials that can be afforded given the budget. The key point is that we cannot rule out the possibility that, for a given budget, the RCT ends up with a higher variance of its impact estimate. Then it may well be further from the truth than even a biased OS. We lack a clear theoretical justification for the claimed (unconditional) "gold standard" hierarchy of methods.

In defense of RCTs, we currently know rather little about the distribution of the biases in OSs, while (as noted) the unbiasedness of an RCT comes with an estimable variance, to facilitate calculation of its confidence interval. This points to the need for more research on the distribution of estimates from OSs, such as by comparing OS estimates with RCTs for the same setting. ${ }^{28}$ It remains, however, that if we insist on only doing RCTs (when feasible) then we may be forgoing OSs that are more often close to the truth. That is surely a high price to pay for unbiasedness.

Greater clarity may well emerge when we know the context. If one knows the setting and program well enough to identify the relevant confounders - the model of how the program works - and can collect data on them, or one can identify measurable deconfounders, then one may well obtain a very reliable impact estimate by observation alone. However, if there is little scope for collecting baseline data on the relevant confounders, and the unit cost of

${ }^{28}$ See, for example, Chabé-Ferret (2018). 
randomized assignment is not too high (so that reasonably large sample sizes are feasible with the available budget), then an RCT has much appeal.

We can go further and ask what design is optimal in the sense of minimizing the MSE, while recognizing our uncertainty about the true model. ${ }^{29}$ Let us assume that at least some of the baseline data are continuous covariates and that we have Bayesian priors on the model uncertainty. Then we can appeal to a result in Kasy (2016), namely that there exists a deterministic (non-random) assignment of treatment status based on the covariates that minimizes the expected MSE. ${ }^{30}$ (A continuous covariate assures a unique optimum assignment of treatment status. With discrete covariates an RCT may do as well, but no better.) Then there is no gain from randomizing the assignment given the covariates (and there will be efficiency gains from taking account of observables in RCTs). By implication, to justify a strong preference for an RCT one needs to attach some intrinsic value to randomization as an end in itself, and be willing to forgo accuracy in getting closer to the true mean impact. ${ }^{31}$

The influence of the randomistas has stemmed in part from the (much-heard) belief that RCTs are the preferred statistical tool when feasible. This review of the underlying theory has cast doubt on that belief. As we will see, other sources of their influence are no less questionable.

\section{The influence of the randomistas on development research}

Early examples of the use of RCTs in social policy contexts include the various experiments on US social policies starting in the 1960s. ${ }^{32}$ With regard to development applications, the 3ie database has 133 published RCTs over the period 1981-1999. The earliest RCT in the database is from a World Bank research project on education interventions (textbooks and radio lessons) to improve the math scores of students in Nicaragua, namely Jamison et al. (1981). ${ }^{33}$ Among the pre-2000 RCTs, that done by the Government of Mexico for the Progresa evaluation, which started in 1997, is an especially notable example. The (generally

\footnotetext{
${ }^{29}$ Following Kasy (2016) this can be recognized as a problem in statistical decision theory, i.e., the choice of an estimation method to minimize a loss function based on the data actually available.

${ }^{30}$ This holds for any Bayesian risk function and for a minimax rule for the worst-case (Kasy, 2016). Kasy provides software to implement the optimal assignment of treatment for minimizing the MSE.

${ }^{31}$ For example, Banerjee et al. (2018) shows that an RCT with sufficient sample size dominates as long as one puts sufficient weight on the welfare of an "adversarial audience" that prefers RCTs under their assumptions. 32 On the history of RCTs in US social policy see the discussions in Burtless (1995) and List and Rasul (2011). Other commentaries on the history of RCTs more generally can be found in Ziliak (2014) and Leigh (2018).

33 Banerjee et al. (2019) claim that the use of RCTs in development was "kick-started" in 1994 in a study by one of the authors (Kremer). However, development RCTs had existed for at least 13 years prior to that.
} 
positive) results in the literature generated by the data from that RCT were influential in the expansion of Conditional Cash Transfers to over 50 countries today. ${ }^{34}$

So, at the beginning of the new Millennium, there was nothing new to the idea of RCTs in development applications. What changed is the popularity of that idea. Annual "RCT production" has been far higher since 2000 (Figure 1). Numerous individual academics and groups have played roles, but one group stands out, the Abdul Latif Jameel Poverty Action Lab (J-PAL). ${ }^{35}$ This was founded in 2003 (as the Poverty Action Lab) and has been based in the Department of Economics at the Massachusetts Institute of Technology (MIT). The founders were Abhijit Banerjee, Esther Duflo and Sendhil Mullainathan. At the time of writing (December 2018), J-PAL's website reports that they have 927 completed and ongoing RCTs in 81 countries. For an academic research group to get that far in just 15 years is nothing short of amazing. On top of its own RCTs, J-PAL has clearly influenced the shift in emphasis in empirical development economics more broadly toward RCTs. Indeed, JPAL's huge RCT output is unlikely to be even a majority of the total count of RCTs today.

The discussion in this section looks first at the reasons for the influence of the randomistas on development research. It then asks if their influence has been justified.

\section{Why have the randomistas had so much influence?}

Propagating the view that (when feasible) RCTs dominate purely observational studies in attempting to infer causation has clearly held sway. The landing page of J-PAL's website tells us that: "Our mission is to reduce poverty by ensuring that policy is informed by scientific evidence." Toward that aim, J-PAL only does RCTs. Strictly that does not imply that JPAL's researchers think that OS is unscientific (and, independently of J-PAL, many J-PALaffiliated researchers have used OS). However, in this context, the phrases "scientific evidence" and (another favorite, including on J-PAL's website) "rigorous evidence" are code for RCTs in the eyes of most readers, and that is plainly intentional. Then the implication is even stronger than the "gold standard" claim: for J-PAL, RCTs are not just top of the menu of approved methods, nothing else is on the menu.

The appeal of RCTs reflects in part the challenges faced in identifying causal impacts by observation alone. Since the 1990s, we have seen a welcome rise in the standards of identification in economics. More critical attention has been given to the validity of IV estimators. It is easy to show that a failure of either of the aforementioned conditions for a valid IV can bias the estimate-possibly more so in some cases than for Ordinary Least Squares (OLS), which treats placement as exogenous. It was not hard for researchers to find

\footnotetext{
34 See Skoufias and Parker (2001) and Fiszbein and Schady (2010).

35 Another prominent group doing and promoting RCTs is the non-profit organization, Innovations for Poverty Action (IPA), founded in 2002 by Dean Karlan (then at Yale). IPA and J-PAL often work together, and clearly have close links. Within international organizations, the most prominent group doing RCTs is the Development Impact and Monitoring (DIME) group at the World Bank; three-quarters of DIME's evaluations have used this method (World Bank, 2016).
} 
exogenous variables that are correlated with selected treatment status (though they still needed to pass the appropriate tests). Accepting the exclusion restriction (that the IV is irrelevant to outcomes given treatment status) on theoretical grounds was often far more challenging. There were some cases in which the IV could be readily accepted, but this was not always so. From the mid-1990s, seminar audiences and referees were regularly pointing to reasons why the IV in specific papers could have an effect on outcomes that is independent of the endogenous variable or the control variables. In due course, some economists started to reject almost any attempt at establishing causality by observational means, with an RCT emerging (it seemed) as the only solution.

If one only wants to know the difference in mean outcomes between those assigned the option for treatment and those not — which is called the Intent-to-Treat (ITT) parameterthen randomization side-steps these problems. Given randomization, the treatment assignment is exogenous, uncorrelated with the regression error term. However, ITT is a rather limited parameter. It is sometimes defended as "policy-relevant" in that the policy is often the assignment of the option for treatment. Yet how would you react to finding that the mean impact is (say) zero among those offered treatment, but positive among those who took it up? Such a finding would surely be of interest to policymakers and citizens. In learning from an RCT, a prospective adopter of the treatment will want to know mean impact for those treated.

Take-up of the (randomly-assigned) treatment is never assured, and it is typically endogenous. So the econometric problem can readily return in practice. The randomistas have a solution: use randomized assignment as the IV for actual treatment. Clearly, take-up requires assignment, so this IV is correlated with treatment status. Since it is random, the IV is also uncorrelated (in expectation) with the error term when the treatment effect is common across the population. (The discussion will return to the complications that can arise when impacts vary in a way that is unknown to the researcher but each participant knows the likely impact, and responds accordingly.)

Beyond these econometric arguments, a number of other factors contributed to the randomistas' growing influence from the early 2000s. Researchers who did not use randomization started to be criticized by the randomistas. Some of this took the form of referees' comments on journal articles, which are not public. Journal editors do not need to accept such critiques, though the leading randomistas appear to have been influential and in due course became quite prominent among the editors and editorial boards of economics journals. At times, the critiques also took a public form, such as the study by Finkelstein and Taubman (2015), which questioned the fact that OS is often used in evaluating health-care delivery policies. This finding was then reported in the New York. Times under the heading "Few Health System Studies use Top Method, Report Says" (Tavernise, 2015; my emphasis), where the "top" is taken to be an RCT. The message here is clear, though it is less clear that 
it is right. Indeed, some public health specialists have argued that there has been too much attention to IEs for individual treatments at the expense of research on health systems. ${ }^{36}$

The leading randomistas also did a good job in teaching others how to use their preferred method. ${ }^{37}$ Development economists got up to speed quickly, as did some NGOs. They have also been steadily raising the bar on what constitutes a good RCT, though the observation of Heckman and Smith (1995) that RCTs get less critical scrutiny than OSs still seems true today.

Another factor enhancing their influence is that J-PAL's founders professed their desire to make the world a better place through evidence-based policymaking. This was J-PAL's declared motivation from the outset. By this view, doing many RCTs lets us figure out what works and what does not, to scale up the former and scale down the latter (Banerjee, 2006). An analogy is drawn with RCT's in clinical trials, as used to find out what drug works best on average (Favereau, 2016).

Some followers have clearly been attracted by the zeal of the leading randomistas. By this view, "... the experimental ethic has been proposed as the way to change the spirit of development" (Donovan, 2018, p.27). Thus, the randomistas can be seen in part as an epistemic movement that attracts its "true believers." 38 The movement's faith in RCTs promises its followers a "quiet revolution" (Banerjee and Duflo, 2011, p.265).

Supporters (including donors) have also been attracted by the simplicity of RCTs - that they are "more transparent and easier to explain" (Duflo, 2017, p.17). It is easier for noneconomists to understand an RCT than the methods often favored for OS, which were also getting increasingly sophisticated, and technically demanding, by the time J-PAL was founded.

\section{Is the randomistas' influence justified?}

As Section 2 argued, the statistical foundations of IE do not tell us that (when feasible) RCTs are invariably more reliable, whatever the context, and so sit at the top of the hierarchy of methods. This appears to be more a matter of faith than science. The rejection of OS in some quarters has clearly been an over-reaction to the challenges faced in identifying causal effects this way.

Nor is the analogy to clinical trials persuasive. It is unclear that the idea of using black-box RCTs to figure out what works and what does not in development is feasible given the dimensionality in both interventions and contexts. Too often, the arguments made for RCTs

\footnotetext{
${ }^{36}$ See, for example, Rutter et al. (2017).

37 An example is the excellent "RCT toolkit" produced by Duflo et al. (2011). The World Bank's Development Impact blog has provided a great deal of useful methodological support for doing RCTs.

38 A reviewer of Leigh (2018) describes the author as a "true believer" and then recounts the various personal choices that Leigh makes based on the results of RCTs (Wydick, 2018).
} 
lack a clear economic rationale for the intervention, or a coherent structure for understanding why it may or may not work (Heckman and Smith, 1995).

While the development randomistas were pointing to clinical trials as the model, medical researchers were taking a more nuanced view. ${ }^{39}$ On the one hand, some of the recent literature suggests that past concerns about bias in causal observational health and medical studies have been exaggerated. On the other, it now seems to be accepted that gains from removing systematic bias need to be weighed against the costs and risks of clinical RCTs.

Yet, putting these points to one side, it must be recognized that the medical context is somewhat different. Economists (and other social scientists) are dealing with people (as individuals and groups) in social and/or economic contexts in which they can be expected to exhibit greater heterogeneity, and almost certainly greater agency, than is likely in clinical trials. We may often know rather little about the specific setting a priori. This also warns against the push for the use of pre-analysis plans in development RCTs, especially in unfamiliar contexts.

Some deeper inferential issues lie under the surface of the randomistas' claims - issues that are known to the experts on both sides but poorly understood more broadly. There is almost certainly some unobserved heterogeneity in the impacts of treatment. There are many sources, including both the circumstances of the individual (such as past experience with the type of intervention) and the effort made by agents (reflecting their beliefs about the impact). ${ }^{40}$ Such heterogeneity raises the question of "impact for whom?" This was answered by Angrist et al. (1996), who showed that the IV is giving the mean impact for a subset of the treated, namely the "compliers," induced to switch their treatment status by the randomized assignment. ${ }^{41}$

When estimating the mean impact on those treated, the validity of randomized assignment as the IV to address selective take-up can be questioned in the presence of behavioral responses to such unobserved heterogeneity in the impacts of treatment (Heckman and Vytlacil, 2005; Heckman et al., 2006). The differing impacts must then be relegated to the regression error term, interacting with the selective take-up of the randomized assignment. Those units with high returns to treatment will be more likely to take it up. Then the interaction effect that has now surfaced in the error term must be correlated with the randomized assignment. The exclusion restriction fails. (Of course, none of this matters if one only wants ITT.)

Identifying the impacts of social programs is rarely easy, with or without randomized assignment. Suppose that the latent characteristics that enhance impact at the individual level also matter to the counterfactual outcomes in an RCT with selective compliance. The choice of estimation method then depends crucially on what impact parameter one is interested in,

${ }^{39}$ Examples of the following points are found in Silverman (2009), Bothwell et al. (2016) and Frieden (2017).

40 On the latter source see Chassang et al. (2012), who study the implications for the external validity of RCTs.

${ }^{41}$ Also see the discussion in Pearl (2009, Chapter 8). 
the type of program one is evaluating and the behavioral responses to that program (Ravallion, 2014). If the latent factors leading to higher returns to treatment are associated with lower counterfactual outcomes then the "IV cure" for endogenous treatment can be worse than the disease. Indeed, the OLS estimator may even be unbiased, despite the selective take-up. The key point is that practitioners need to think carefully about the likely behavioral responses to heterogeneous impacts in each application-similarly to any OS.

The design of RCTs in practice can also pose threats to identification. The randomized assignment is sometimes done across clusters of individuals, such as villages. Some clusters get the treatment and some do not. Those within a selected treatment cluster are left free to take up the treatment as they see fit. This is a now classic design in development applications. ${ }^{42}$ It runs into a problem whenever there is likely to be interference within the clusters whereby non-participants in the selected treatment clusters are impacted by the program. For example, the cluster RCT in Ravallion et al. (2015) used an entertaining movie to teach people their rights under India's National Rural Employment Guarantee Act. It was impossible to enforce ticket assignments; the movie had to be shown in public places-often open areas of the village. So access to the movie was randomly assigned across villages, with people free to choose whether to watch it. Some did not, but (of course) they can talk with others who did, and this turned out to be an important channel of impact on knowledge (more so for some groups than for others). The cluster randomization had to be combined with a behavioral model of why some people watched the movie (Alik-Lagrange and Ravallion, 2018). Only then could the direct treatment effect (watching the movie) be isolated from the indirect effect (living in a village with access to the movie). In this example, the spillover effects within clusters violate the exclusion restriction, so the use of cluster assignment as the IV for individual take-up performs poorly.

The generic point is that - contrary to the claims about clean identification of the mean causal impact using randomized assignment—assumptions and models are often required in practice. It does not help that the behavioral assumptions underlying studies using randomization are not always explicit (Keane, 2010); structural approaches, in contrast, force this to happen.

Some concerns have received less attention in the literature than they merit. One example is Hawthorne effects, whereby monitoring in an experiment changes behavior. (For example, if you know you are in the control group you may be inclined to seek a substitutable treatment. Or some in the treatment group may try to please the experimenter. ${ }^{43}$ ) RCTs in economics do not often have the double-blind feature common to clinical trials, so biases associated

\footnotetext{
${ }^{42}$ Of course, if one can use double randomization — randomizing within villages as well as between them — then one can readily address this type of interference (Baird et al., 2017). Cluster randomizations are designed for situations in which within-cluster randomization if not feasible. Such situations are common in development applications.

43 One RCT randomly assigned knowledge about the experimenter's intent, but did not find any significant effect (Mummolo and Peterson, 2018). Further tests of this sort are needed.
} 
with monitoring are more likely, and they merit more attention in development applications. ${ }^{44} \mathrm{~A}$ second example is the topic of the next section.

\section{Taking ethical objections seriously}

Ethical concerns are never far removed from policymaking. There are two dangers of not taking the ethics of evaluation seriously. First, morally unacceptable evaluations may end up being done, and possibly more often in poor places with vulnerable populations and weak institutions for protecting their rights. Second, socially valuable evaluations may be blocked as too risky politically, largely in ignorance of the benefits.

RCTs have been criticized on the grounds that "randomizers are willing to sacrifice the wellbeing of study participants in order to 'learn"' (Ziliak and Teather-Posadas, 2016). ${ }^{45}$ Critics have often pointed out that in an RCT some people who need the treatment are not getting it, while others receive a treatment they do not need. The criticism is also heard that RCTs in poor countries do not get the same ethical scrutiny that is expected (though by no means assured) in rich countries. ${ }^{46}$ Baele (2013) argues that the development randomistas have not paid enough attention to the ethics of their RCTs. Some defenders of RCTs have been strident in rejecting these concerns; for example, one commentator dismissed ethical criticisms of RCTs as "garbage" (Fiennes, 2018). Others have offered a more cautious ethical defense of RCTs against their critics, including Glennerster and Powers (2016).

Ethical validity is not a serious issue for all IEs. Sometimes an IE is built onto an existing program such that nothing changes about how the program works. The IE takes as given the way the program assigns its benefits. So if the program is deemed to be ethically acceptable then this can be presumed to hold for the IE. We can dub these "ethically-benign evaluations."

Other IEs deliberately alter the program's (known or likely) assignment mechanism-who gets the program and who does not. Then the ethical acceptability of the intervention, as it normally works at scale, does not imply that the evaluation is ethically acceptable. Call these "ethically-contestable evaluations." The main examples in practice are RCTs. Scaled-up programs almost never use randomized assignment, so the RCT has a different assignment mechanism, with potentially large differences in the benefits, given the likely heterogeneity in impacts. An RCT can be contested ethically even when the real program is fine.

It is surely a rather extreme position (not often associated with economists) to say that good ends can never justify bad means. It is ethically defensible to judge processes in part by their outcomes; indeed, there is a long and respected view in moral philosophy that consequences often trump processes—with utilitarianism as the leading example. It is not inherently

\footnotetext{
44 This aspect of the difference between economic RCTs and clinical RCTs is discussed further in Favereau (2016). For a useful overview of the Hawthorne effect in the health field see Friedman and Gokul (2014). 45 Also see the comments in Barrett and Carter (2010), Baele (2013) and Mulligan (2014).

46 In the US, the ethics of using RCTs for the evaluation of Federal social policies has not received the same attention as for clinical trials. Blustein (2005) discusses the reasons.
} 
"unethical" to do an RCT as long as this is deemed to be justified by the expected benefits from new knowledge. However, the consequential benefits do need to be carefully weighed against the process concerns. This is especially so in the many instances in which there is a feasible, and benign, alternative OS.

Ethics has been much discussed in medical research where the principle of equipoise requires that there should be no decisive prior case for believing that the treatment has impact. ${ }^{47}$ Only if we are sufficiently ignorant about whether it is better to be in the treatment group or the control should we randomize at all, or continue with an RCT.48 If evaluators are to take ethical validity seriously then some development RCTs will have to be ruled out as unacceptable given that we are already reasonably confident of the outcomes- that the gain from knowledge is not likely to be large enough to justify the ethically-contestable research. ${ }^{49}$

The principle of equipoise is rarely applied to RCTs for development and social policies. Indeed, there may well be a tendency in the opposite direction. A recent call-for-proposals from a prominent philanthropic funder gave explicit preference to any RCT proposal "That is backed by highly-promising prior evidence, suggesting it could produce sizable impacts on outcomes..." (Arnold Foundation, 2018, p.2). At one level, one can understand the funder's preference, given that RCTs are costly and there is a desire to have impact with limited resources. Some ex ante filters of this sort make sense. (One would not want to fund an RCT for an intervention that is unlikely to turn out to be feasible on the ground.) However, this example points to a tension between donor objectives and ethical concerns. Ex ante confidence of "sizeable impacts on outcomes" leaves one worried about withholding a treatment from those who need it (and wasting treatment on those who do not). This also points to a concern about the funding processes determining what gets evaluated. The next section returns to this topic.

There have been some ethical defenses of RCTs. One view is that RCTs are justified whenever rationing is required; when there is not enough money to cover everyone, it is argued that randomized assignment is a fair solution..$^{50}$ This makes sense when information is very poor. In some development applications, we may know very little ex ante about how best to assign participation to maximize impact. Nevertheless, when alternative allocations are feasible and one does have prior information about who is likely to benefit, it is surely fairer to use that information, and not randomize, at least unconditionally.

It has also been argued that the method of conditional randomization (also called "blocked" or "stratified" randomization) can relieve ethical concerns. The idea here is that one first selects eligible types of participants based on prior knowledge about likely gains, and only

\footnotetext{
47 There is a good discussion in Freedman (1987), which introduced the principle of equipoise in clinical trials. In the context of development IEs see Baele (2013) and McKenzie (2013).

48 The "we" here is best thought of as a set of people with sound knowledge of the relevant literature and experience. This is sometimes called "community equipoise."

49 See the examples discussed in Barrett and Carter (2010), Ziliak and Teather-Posadas (2016) and Narita (2018).

${ }^{50}$ See, for example, Goldberg's (2014) comments on Mulligan (2014). The same point is made by Fiennes (2018).
} 
then randomly assigns the intervention, given that not all can be covered. For example, if one is evaluating a training program or a program that requires skills for maximum impact one would reasonably assume (backed up by some evidence) that prior education and/or experience would enhance impact, and then design the evaluation accordingly. This has ethical advantages over pure randomization when there are priors about likely impacts.

There is a catch. The set of things observable to the evaluator is typically only a subset of what is seen on the ground. At (say) village level, there will often be more information than is available to the evaluator-information revealing locally that the program is being assigned to some who do not need it, and withheld from some who do. But whose information should decide the matter? Pleading ignorance seems a lame excuse for an evaluator when other stakeholders do in fact know very well who is in need and who is not.

It has also been argued that encouragement designs are less contentious ethically. The idea is that nobody is prevented from accessing the primary service of interest but the experiment instead randomizes access to some form of incentive or information. This does not remove the ethical concern - it merely displaces it from the primary service of interest to another space. Ethical validity still looms as a concern when the encouragement is being deliberately withheld from some people who would benefit and given to some who would not.

An example is the RCT in Bertrand et al. (2007). One treatment arm provided a large financial reward to those participants who could quickly obtain a driver's license in Delhi India, which facilitated bribes to licensing officials. The RCT did not pay bribes directly or give out licenses to people who did not verifiably know how to drive. However, these were predictable outcomes. The expected gain from this RCT was a seemingly clean verification of the proposition that corruption happens in India and has real effects. There does not seem to have been any serious prior doubt about the truth of that claim.

There may be design changes to RCTs that can address ethical concerns. One option is to switch to an "equivalence trial" for which the control group gets what is thought to be the next best treatment option, rather than nothing or a placebo. Another option is adaptive randomization. This is feasible when there is a sequencing of assignment, with observed responses at each step. Adaptive randomizations change the assignment along the way, in the light of evidence collected on impacts or covariates of impact. ${ }^{51}$ Narita (2018) has proposed an interesting market-like adaptive design for social experiments, whereby one takes account of each participant's Willingness-to-Pay for the chance of treatment, given prior knowledge about impacts. ${ }^{52}$ Unlike a classical RCT, one ends up with a Pareto efficient experiment, though with similar statistical properties for the impact estimates. At the time of writing, this idea does not appear to have been implemented in the field.

\footnotetext{
51 These are getting serious attention in biomedical research. For example, the US Food and Drug Administration (2010) has issued guidelines for adaptive evaluations. Also see Cox and Reid (2000, Chapter 3).

52 Also see Chassang et al. (2012) and the discussion in Özler (2018).
} 
In the US and elsewhere, Institutional Review Boards (IRBs) have become common for proposed studies with human subjects. There is a designated IRB for most research institutions. They are largely self-regulating. Beyond occasional anecdotes, there does not appear to have been a systematic assessment of how well IRB processes have worked for development RCTs. One thing seems clear: IRBs need to give more attention to assessing the expected benefits of an ethically-contestable evaluation given prevailing knowledge. Syntheses of current knowledge (including from IEs) can help and these are becoming more common. ${ }^{53}$

If pressed, many randomistas acknowledge the ethical concerns, though they rarely give them more than scant attention. They assume that their RCTs generate benefits that outweigh such concerns. Whether that is true is rarely obvious. We should also ask how well research efforts match the knowledge gaps relevant to fighting poverty. Imbalances of this sort raise further ethical concerns, given pressing development challenges and limited resources for research. The next section takes up these issues.

\section{Relevance to policymaking}

While there is clearly a lot more to good policymaking than good evidence, policymakers increasingly turn to evidence, hoping to inform their choices, and win political debates. The policy-relevance of evaluative research matters.

To my knowledge, there has not yet been a comprehensive and objective assessment of the influence on development policy of all those RCTs. Nonetheless, one can point to examples of policy-relevant research using RCTs. To give just one example, Banerjee et al. (2014) used RCTs in six countries (Ethiopia, Ghana, Honduras, India, Pakistan, Peru) to evaluate the long-established approach taken against poverty by BRAC using a combination of transfers (assets and cash) targeted to the poorest with literacy and skill training. ${ }^{54}$ The researchers found sustained economic gains from adopting BRAC's approach some three years after the initial asset transfer, and one year after the disbursements finished. If one is willing to extrapolate the earnings gains into the distant future- though this is clearly a strong assumption - then their present value often exceeds the cost of the BRAC-type program (Banerjee et al. 2014).

Without aiming to provide a comprehensive assessment, this discussion points to some limitations of RCTs for informing development policy, drawing on the literature.

\footnotetext{
53 These are sometimes referred to as systematic reviews; see for example, the $\underline{3 i e}$ searchable database and the Campbell Collaboration on such reviews.

54 BRAC now stands for Building Resources Across Communities. The NGO started in Bangladesh (where it was once called the Bangladesh Rural Advancement Committee) but now works in many countries.
} 


\section{Policy-relevant parameters:}

Even under ideal conditions, an RCT is only well-suited to estimating one parameter of interest to policymakers, namely the mean impact. In reality, there will often be both gainers and losers, depending on the characteristics of participating units (and, as noted, some of those characteristics are unobserved to the analyst, though still motivators of behavior, including whether or not to take up the treatment). There is a distribution of impacts. Policymakers may want to know what proportion of the population benefit, and what proportion lose, or what types of people gain and what types lose. Identifying these policyrelevant parameters will typically require more data and more structural-econometric methods. A full-blown structural model need not be essential for addressing the question of interest, but (at the other extreme) an RCT will rarely deliver what is needed. ${ }^{55}$

There are ways of reliably learning more about individual impacts than simply their mean. For example, the Local Instrumental Variables estimator proposed by Heckman et al. (2006) aims to identify the marginal treatment effects (MTEs) at all values of the empirical probability of being treated. Unlike a standard RCT, "selective trials" allow one to identify the MTEs by basing the probability of assignment to treatment (rather than control) on agents' expressed willingness to pay (Chassang et al., 2012). One can then aggregate up to get the mean impact, as would be identified by an RCT. But one learns a lot more than the average impact. Sometimes it is also possible to ask counterfactual questions in surveys, as in Murgai et al. (2016). Then one can learn more about the distribution of impacts, though (of course) there are measurement errors in survey responses, so some averaging will almost certainly be required.

An aspect of performance that is often of interest to policymakers is who benefits from the program, as determined (in part) by the assignment mechanism proposed in its design. If it is demand driven, what are the characteristics of those choosing to take it up? If it is rationed, to whom? Answering such questions is the first stage in an important class of OS methods using matching, namely constructing a statistical model of who gets the program and who does not. ${ }^{56}$ Of course, if it is an RCT then, in expectation, the assignment is not predictable, so nothing can be learnt about the types of people likely to participate when the program is scaled up.

The RCT might be used to assess likely impact ex ante, and then later do a separate IE of the actual program at scale, possibly using an observational-matching estimator. However, given selective take-up and heterogeneous impacts one has essentially evaluated two different programs, only one of which is actually implemented by the government. It is not hard to guess which will be of greater interest to policymakers. Will the second evaluation be done? Probably not if one takes the "gold standard" view.

\footnotetext{
55 See the discussions in Heckman et al. (2006) and Heckman and Urzúa (2010).

56 This refers to propensity-score matching. The predicted values of that model are the "propensity scores" used in selecting observationally-balanced treatment and comparison groups (Rosenbaum and Rubin, 1983).
} 
At the heart of the problem of learning about policy effectiveness is that an RCT is a rather artificial construction, unlike almost any imaginable real-world policy.

\section{External validity}

Policymakers naturally want to learn how a trial intervention in one specific setting might perform in other settings. This is a question about the external validity.

External validity can be in doubt for a number of reasons, including monitoring effects, general equilibrium effects, sampling problems and specific care in providing the treatment in the RCT (Duflo et al., 2008). Such issues are often ignored in papers documenting development RCTs, or the issues are only given a superficial treatment. For the majority of the 54 development RCTs published in eight economics journals (2009-14), Peters et al. (2018) find that the sources of external invalidity are not addressed and the information to address them is not provided. If different RCTs on a given intervention tended to agree then we can be more confident about external validity. But that is not the case. Vivalt (2017) has documented the variance found in the impact estimates for a given program across settings (and even types of evaluators). Her findings warn against generalizations. As Vivalt also notes, poor documentation of contextual factors in impact evaluations does not help. Pritchett and Sandefur (2015) provide examples (for microcredit schemes) in which a (presumed) internally-valid RCT done in one context is inferior to an OS for predicting impact in another context. Not all of this variability in estimates is due to heterogeneity in the true impacts; an estimate for seven microcredit RCTs found that $60 \%$ of the variability is due to sampling variation (Meager, 2018). In practice, policy makers will not be able to easily distinguish sampling variation from true impact variability.

The advantages of working with NGOs in doing RCTs (Section 2) have also raised questions about external validity. An example is found in an RCT on schooling in Kenya. Randomly chosen schools were given the resources to hire an extra teacher working on a short-term contract (Duflo et al., 2015). Children with the contract teachers were found to do significantly better in test scores than those with regular civil-service teachers. This experiment was implemented by a local NGO. However, Bold et al. (2013) attempted to replicate this at scale, using a follow-up RCT, but this time with an arm implemented by the government (as well as one by the NGO). This revealed that it was NGO-implementation that led to test-score gains, not the type of teacher. The teacher-effect vanished.

A "black box" reduced-form estimate (whether from an RCT or OS) is not very informative for many purposes of policymaking. Learning from RCTs poses specific problems. Consider how we might learn about scaling up from an RCT (which is surely an important aim). An RCT randomly mixes low-impact people (for whom the program has little benefit) with high-impact people, based on latent attributes. It is plausible that the scaled-up program will have higher representation from the high-impact types, who will be attracted to the program. ${ }^{57}$ Given this purposive selection based on the (heterogeneous) impacts, the

\footnotetext{
${ }^{57}$ This is an instance of what Heckman and Smith (1995) dubbed "randomization bias."
} 
national program is fundamentally different to the RCT, which may contain little useful information for scaling up. This reflects a more general point made by Moffitt (2006) that many things can change-inputs and even the program itself_-on scaling up a pilot study.

One approach is to repeat the IE in different contexts. For example, using an observational method, Galasso and Ravallion (2005) studied the performance of Bangladesh's Food-forEducation program in each of 100 villages and correlated the results with characteristics of those villages. The differences in performance were partly explicable in terms of observable village characteristics, such as intra-village land inequality (with more unequal villages being less effective in reaching their poor). Not allowing for such differences has been seen as a serious weakness in past evaluations. ${ }^{58}$

Looking inside the black box of an IE can throw useful light on its external validity. This will often require information external to the original evaluation design. An example is the Proempleo RCT by Galasso et al. (2004). Vouchers for a wage subsidy were randomly assigned across people currently in a workfare program, with a randomized control group. The theory is that the wage subsidy will reduce labor costs to the firm and so make hiring the worker more attractive. The RCT found a significant impact on employment. However, subsequent checks against administrative records revealed a very low take-up of the wage subsidy by firms. Proempleo did not work the way the theory had intended. Follow-up qualitative interviews with firms and workers indicated that the vouchers had credential value to workers - " "letter of introduction" that few people had (and the fact that it was allocated randomly was a secret locally in this RCT). This could not be known from the RCT, but required supplementary observational data. (And this had not been anticipated by the researchers ex ante, so rigid adherence to a pre-analysis plan would have missed a crucial, policy-relevant, aspect of why the program had impact.) The extra data also revealed the importance of providing information about how to get a job (rather than wage subsidies per se), which carried implications for scaling up.

Some researchers have been using randomization (either of the intervention or of some key determinant of its placement) to throw light on deeper structural parameters. For example, Todd and Wolpin (2006) use the aforementioned RCT for Progresa in Mexico to model the dynamic behavioral responses to the schooling incentive provided by that scheme. Such research can help us understand a program's impacts and facilitate simulations of alternative policy designs. Todd and Wolpin show that a switch of the Progresa subsidy to higher levels of schooling would enhance overall impacts. In a similar vein, there is scope for using an RCT to test one or more key links in the "theory of change" underlying a program's rationale, even if the tool is not applicable to the program itself. This echoes the arguments of Heckman (1992) on the scope for more ambitious, "interesting," experiments informed by theory.

\footnotetext{
${ }^{58}$ See for example the comments by Moffitt (2004) on trials of welfare reforms in the US.
} 


\section{Knowledge gaps}

To help antipoverty policymaking, researchers should ideally be filling the gaps between what we know about the effectiveness of policies and what policymakers need to know. This is clearly not happening as well as we might hope. ${ }^{59}$

Why do these knowledge gaps exist? There are random factors but there are also more systematic "knowledge market failures" (2009b). One source is the existence of externalities in evaluations. There is evidence that having an impact evaluation in place for an ongoing development project can help improve some aspects of its implementation, such as its speed of disbursement (Legovini et al., 2015). However, the knowledge gains from an IE spillover to future projects, which (hopefully) draw on the lessons learnt from prior evaluations. Current project managers cannot be expected to take proper account of these external benefits when deciding how much to spend on evaluating their own project. There are clearly larger externalities for some types of evaluations, such as those that are more innovative - the first of their kind. The externalities in evaluation also play a role in the "myopia bias" that has been noted in development IEs, such that long-term evaluations are rare (Ravallion, 2009b).

Knowledge market failures also stem from publication biases originating in both the selection processes of journal editors and the behavior of authors. Null results are less likely to be published or even written up. ${ }^{60}$ Subsequent replications of experiments often find less strong effects. ${ }^{61}$ Plainly, these practices distort knowledge. ${ }^{62}$ The dynamics of publication processes are a further source of persistence in knowledge gaps. Errors occur in the literature and it can take time to correct them. In recognition of its originality, the first paper on a topic may well be published prominently. Subsequent papers will tend to be relegated to lesser journals, cited less often, or may even have a hard time being published at all. The

\footnotetext{
${ }^{59}$ For example, Kapur (2018) recounts an interview with a former Chief Economic Advisor of the Government of India (GOI): "When asked how many of these expensive RCTs had moved the policy needle in India, Arvind Subramanian, Chief Economic Advisor, GOI, was hard pressed to find a single one that had been helpful to him in addressing the dozens of pressing policy questions that came across his table." Also see the comments in Basu (2014) (another ex Chief Economic Advisor of GOI.)

60 Among 221 social science studies it was found that "Strong results are 40 percentage points more likely to be published than are null results and 60 percentage points more likely to be written up" (Franco et al., 2014, p.1502). The distribution of reported p-values in papers published in the AER, QJE and Journal of Political Economy suggests that researchers tend to make specification choices that inflate the significance of their results to get over a " $5 \%$ significance" hurdle (Brodeaur et al., 2016). Christensen and Miguel (2018) survey the evidence on these biases in published economic research and discuss how the biases might be reduced.

${ }^{61}$ Camerer et al. (2016) replicated 18 laboratory experiments published in the American Economic Review (AER) and Quarterly Journal of Economics (QJE). On average, the replicated effect size was one third lower than the original.

${ }^{62}$ Basu (2014, p.462) elaborates this point. With reference to whether medicine (M) improves school participation $(\mathrm{P})$ he shows that, in a stylized situation in which there is no true impact of M on P: "With 10,000 experiments it is close to certainty that someone will find a firm link between $\mathrm{M}$ and $\mathrm{P}$. Hence, the finding of such a link shows nothing but the laws of probability being intact. Yet, thanks to the propensity of journals to publish the presence rather than the absence of "causal" links, we get an illusion of knowledge and discovery where there are none."
} 
author of the original paper becomes the gatekeeper of knowledge on the topic. While the gatekeeper is not unpassable, she can have considerable influence. But the first paper may not have got it right. On top of this, the incentives for effort at replication appear to be weak in economics. ${ }^{63}$ (Yet in the sciences, failures to replicate have been common; see Ioannidis, 2005.) Thus, the first draw from the distribution of impacts can have a lasting distortionary effect on accepted knowledge.

External invalidity also raises concerns about the process of knowledge accumulation. Even if the first paper came close to the truth in the specific context, it may have limited validity in different circumstances. When the topic concerns the impact of a policy, or an issue that is very relevant to that impact, policy knowledge will tend to be skewed accordingly.

These are generic concerns, not confined to RCTs. However, the gold standard methodhierarchy could well make things worse, as we will now see.

\section{Matching research efforts with policy challenges}

Knowledge gaps also stem from miss-alignments of evaluative effort. One aspect of this is that development evaluators too often ignore the scope for fungibility. As is well known, recipients (governmental or not) can re-allocate their own efforts in response to new funds, such as development aid. Donors are often implicitly funding something else. A less wellknown implication is that donors and higher levels of government may well be evaluating the wrong thing from the point of view of assessing their own impact. Then evaluative efforts are miss-aligned with development efforts.

RCTs are not to be blamed for this. However, methodological preferences on the part of evaluators can readily reinforce the miss-alignment. The development randomistas have had both output and substitution effects on knowledge. There is at least the suggestion of a positive output effect in the fact that we have seen a great many more RCTs (Figure 1). However, as discussed already, neither the internal nor the external validity of these development RCTs is beyond doubt. We do not know the counterfactual—what we would have learnt if those resources (financial and human capital) had been deployed elsewhere.

The substitution effect relates to the methods used. Take, for example, the World Bank. While the earliest RCT in the 3ie database is by the Bank, until the early 2000s the tool was seen as only one of many options for IE. Since then there has been a marked switch in favor of RCTs within the Bank, which has been applauded by some observers; for example, an editorial in The Lancet declared that "The World Bank is finally embracing science." (Lancet, 2004, p.731).64 The Bank's Independent Evaluation Group (IEG) reports that over $80 \%$ of

\footnotetext{
${ }^{63}$ See the discussion in Rodrik (2009). Since then, 3ie has supported replication efforts for development IEs through its Replication Window and its Journal of Development Effectiveness.

${ }^{64}$ On the influence of RCTs at the World Bank see Webber and Prouse (2018).
} 
the IEs starting in 2007-10 used randomization, as compared to 57\% in 2005-06 and only $19 \%$ in prior years (World Bank, 2012).

Even if we presume that all those RCTs had a positive output effect on knowledge, the substitution effect could well work in the opposite direction. There are three aspects of the substitution effect. First, the emphasis on identifying causal impacts using RCTs has deflected attention from OSs, including descriptive research, which is surely undervalued in development research today. Some of the lessons emerging from RCT research papers could have been derived from good "thick" descriptions (using qualitative and/or quantitative methods).

Second, there is a concern that the emphasis on assigned individualized programs (using both RCTs and OSs) has deflected attention from systemic research, typically using structural models. In economics more broadly, the decline in attention to structural work in teaching and research has been noted by Keane (2010) and others. This has also been a raised as a specific concern for research on public health (Rutter et al., 2017).

Third, a problem in evaluating the impact of the portfolio of development policies is that randomization is clearly only feasible for a non-random sub-set of policies and settings. Observational studies are the only option for the remainder. The implication is that we lose our ability to make inferences about a broad range of policies if we rely solely on RCTs. Randomization tends to be better suited to relatively simple programs, with clearly identified participants and non-participants, relatively short time horizons, and with little scope for the costs or benefits to spillover to the group of non-participants. In short, the tool is better suited to private goods, which are easy to assign across individual households, but are less able to handle public goods with benefits shared across many people (Hammer, 2017). There are exceptions (such as certain local public goods). However, it is generally far more difficult to randomize the location of medium- to large-scale infrastructure projects and seemingly impossible to randomize sectoral and economy-wide reforms. This makes the tool of limited use for some of the core activities in almost any country's development strategy. Pressing global issues such as climate change also call for a different approach.

Focusing on neatly assignable private goods begs the question of what the economic rationale is for the "policy" being evaluated. Would not markets provide this private good efficiently, eliminating the need for any impact evaluation? There may be good reasons why the IE for a private good is needed in specific contexts, but one does not often hear them from the randomistas. Redistributive goals are often mentioned, but in a rather casual way. Distributional impacts are rarely addressed with any rigor, or even identified as outcomes. In short, the public economics is largely missing.

Of course, no single tool can cover all applications. The question here is whether we have a reasonable balance today between research effort and policy challenges. The (questionable) hierarchy of methods advocated by the randomistas makes it harder to attain that balance. Indeed, even for private goods, the very idea of randomized assignment is antithetical to the goals of many development programs, which typically aim to reach certain types of people or 
places. (In delivering cash transfers to poor people, governments will hopefully be able to do better than a random assignment.)

The aforementioned IEG report documents the unbalanced assignment of World Bank IEs across the sectors of its operations, and the seemingly poor fit of the evaluation portfolio to the Bank's sectoral and development priorities (World Bank, 2012). Though I have not seen evidence, I suspect that there is also an imbalance in the assignment of IEs according to the likely duration of project benefits. Long-term impact evaluations of World Bank development projects are rare, despite the claims made about longer-term impacts. I can testify from personal experience how hard it is to organize and implement long-term IEs at the World Bank. ${ }^{65} \mathrm{It}$ is plausible that favoring RCTs exacerbates a myopia bias in development knowledge.

This is not just happening in the World Bank. The sectoral bias in the use of RCTs more broadly is evident from the results of Cameron et al. (2016) who provide a cross-tab of over 2,200 published impact evaluations (in the aforementioned 3ie database) by method and sector. ${ }^{66}$ Overall, about two-thirds of these evaluations use RCTs, but the RCTs tend to be concentrated in certain sectors, notably education (58\% used an RCT), health, nutrition and population (83\%; 93\% in health alone), information and communications technology (67\%), and water and sanitation $(72 \%)$. OS is more common - with under one-third using an RCT - in agriculture and rural development, economic policy, energy, environment and disaster management, private sector development, transportation, and urban development. The production of impact evaluations has also been uneven geographically (even allowing for population). India has had the largest absolute number but Kenya has had the most per capita. ${ }^{67}$ The geography of RCT placement is influenced by researcher connections with local NGOs.

There are both supply and demand sides to this bias. On the supply side of evaluations, the reality today is that, enamored by the promise of cleanly identifying a causal effect, many economists and other social and political scientists have been searching for something to randomize. If randomization is not feasible, they turned to ask other questions.

On the demand side, governments (and development agencies) are largely free to choose what is evaluated. One concern here is that they do not always know what evidence they need. ${ }^{68}$ Politics also plays a role. They may be drawn to pick programs for which there is little risk that a negative appraisal will hurt politically, or to pick those that do matter but for which there are good reasons to be confident of a politically acceptable result (again raising ethical concerns). Other important development programs will not be evaluated. The risks are plain.

\footnotetext{
65 This largely based on the study reported in Chen et al. (2009).

${ }^{66}$ In addition to RCTs the methods identified are difference-in-differences, instrumental variables, regression discontinuity and matching. Multiple methods are allowed in the counts.

${ }^{67}$ For details see Cameron et al. (2016) and Sabet and Brown (2018).

${ }^{68}$ See, for example, the discussion in Duflo (2017).
} 
Addressing these concerns calls for more strategic evaluation agendas, not driven by the methodological preferences of researchers. We have started to see more strategic agendas for RCTs. This is welcome, though the strategies are still led by academic researchers, based on their interests and devoted to one tool. If we are really concerned about obtaining unbiased estimates of the impact of the portfolio of development policies it would surely be better to carefully choose (or maybe even randomly choose!) what gets evaluated, and then find the best method for the selected programs, with an RCT as only one option. That is what is called for if we take seriously the goal of obtaining an unbiased assessment of overall development impact. Research can serve that goal, but it is unlikely to happen automatically.

\section{Conclusions}

We are seeing a welcome shift toward a culture of experimentation in fighting poverty, and addressing other development challenges. RCTs have a place on the menu of tools for this purpose. However, they do not deserve the special status that advocates have given them, and which has so influenced researchers, development agencies, donors and the development community as a whole. To justify a confident ranking of two evaluation designs, we need to know a lot more than the fact that only one of them uses randomization.

The rising popularity of RCTs has rested on a claimed hierarchy of methods, with RCTs at the top as the "gold standard." This does not survive close scrutiny. Despite frequent claims to the contrary, an RCT does not equate counterfactual outcomes between treated and control units. The absence of systematic bias does not imply that the experimental error in a one-off RCT is less than the error in an alternative observational study. We obviously cannot know that. Among the feasible methods in any specific application (with a given budget for the evaluation), the RCT option need not minimize mean squared error. When a biased observational study is feasible with a sample size that is sufficiently greater than for an RCT in the same setting, the observational study may well be closer to the truth.

There is still ample scope for useful observational studies, informed by theory. Yes, there is model uncertainty, though generally not as much as the randomistas assume. Moreover, when we look at RCTs in practice, we see them confronting problems of miss-measurement, selective compliance and contamination. Then it becomes clear that the tool cannot address the questions we ask about poverty, and policies for fighting it, without making the same type of assumptions found in observational studies-assumptions that the randomistas promised to avoid.

RCTs are also ethically contestable in a way that experimentation using observational studies is not. The ethical case against RCTs cannot be judged properly without assessing the expected benefits from new knowledge, given what is already known. Review boards need to give more attention to the ex-ante case for deliberately withholding an intervention from those who need it, and deliberately giving it to some who do not, for the purpose of learning. There may be a good case in specific contexts, based on the limitations of existing knowledge, but the case does need to be made in a credible way and not just taken for granted. 
The questionable claims made about the superiority of RCTs as the "gold standard" have had a distorting influence on the use of impact evaluations to inform development policymaking. The bias stems from the fact that randomization is only feasible for a nonrandom subset of policies. When a program is community- or economy-wide or there are pervasive spillover effects from those treated to those not, an RCT will be of little help, and may well be deceptive. The tool is only well suited to a rather narrow range of development policies, and even then it will not address many of the questions that policymakers ask. Advocating RCTs as the best, or even only, scientific method for impact evaluation risks distorting our knowledge base for fighting poverty. That risk was one of the main concerns in Ravallion (2009a), and the experience since then has reinforced that concern.

While we have seen much progress over the last 10 years, there are still grounds for doubting whether evaluative research on development fits well with the policy challenges now faced. This paper has argued that a better alignment requires:

- Abandoning claims about an unconditional hierarchy of methods, with RCTs at the top, and making clear that "scientific" and "rigorous" evidence is not confined to RCTs.

- Demanding a clear and well-researched ex ante statement of the expected benefits from an RCT, to be weighed against the troubling ethics.

- Making explicit the behavioral assumptions underlying randomized evaluations, similarly to the standards of structural approaches.

- Going beyond mean causal impacts, to include other parameters of policy interest and better understanding the mechanisms linking interventions to outcomes.

- Viewing RCTs as only one element of a tool kit for addressing the knowledge gaps relevant to the portfolio of development policies. 


\section{References}

Alik Lagrange, Arthur, and Martin Ravallion, 2018, "Estimating Within-Group Spillover Effects Using a Cluster Randomization: Knowledge Diffusion in Rural India," Journal of Applied Econometrics, forthcoming.

Angrist, Joshua, Guido Imbens and Donald Rubin, 1996, "Identification of Causal Effects Using Instrumental Variables," Journal of the American Statistical Association, XCI: 444-455.

Baele, Stéphane, 2013, "The Ethics of New Development Economics: is the Experimental Approach to Development Economics Morally Wrong?," Journal of Philosophical Economics 7(1): 1-42.

Baird, Sarah, Aislinn Bohren, Craig McIntosh and Berk Özler, 2017, "Optimal Design of Experiments in the Presence of Interference," Review of Economics and Statistics, forthcoming.

Banerjee, Abhijit, 2006, "Making Aid Work. How to Fight Global Poverty_Effectively," Boston Review, July/August.

Banerjee, Abhijit, and Esther Duflo, 2009, "The Experimental Approach to Development Economics," Annual Review of Economics 1: 151-178. and ,2011, Poor Economics: A Radical Retbinking of the Way to Fight Global Poverty, New York: Public Affairs. and 2017, "Pushing Evidence-Based Policymaking for the Poor," Livemint, October 16.

Banerjee, Abhijit, Sylvain Chassang, Sergio Monero, and Erik Snowberg, 2018, “슬 Theory of Experimenters." NBER Working Paper 23867.

Banerjee, Abhijit, Esther Duflo and Michael Kremer, 2019, "The Influence of Randomized Controlled Trials on Development Economics Research and on Development Policy," in Kaushik Basu, David Rosenblatt and Claudia Paz Sepulveda (eds), State of Economics, State of the World, MIT Press, forthcoming.

Banerjee, Abhijit, Dean Karlan, and Johnathan Zinman, 2014, "Six Randomized Evaluations of Microcredit: Introduction and Further Steps," American Economic Journal: Applied Economics 7(1): 1-21.

Barrett, Christopher, and Michael Carter, 2010, "The Power and Pitfalls of Experiments in Development Economics: Some Non-random Reflections," Applied Economic Perspectives and Policy 32(4): 515-548.

Basu, Kaushik, 2014, "Randomization, Causality and the Role of Reasoned Intuition," Oxford Development Studies 42(4): 455-472.

Bertrand, Marianne, Simeon Djankov, Rema Hanna, and Sendhil Mullainathan, 2007, "Obtaining a Driver's License in India: An Experimental Approach to Studying Corruption," Quarterly Journal of Economics 122(4): 1639-1676.

Bethlehem, Jelke, 2009, Applied Survey Methods: A Statistical Perspective. New York: Wiley.

Blustein, Jan, 2005, "Toward a More Public Discussion of the Ethics of Federal Social Program Evaluation," Journal of Policy Analysis and Management 24(4): 824-852.

Bold, Tessa, Mwangi Kimenyi, Germano Mwabu, Alice Ng'ang'a, and Justin Sandefur, 2013, "Scaling Up What Works: Experimental Evidence on External Validity in Kenyan 
Education," CGD Working Paper 321, Center for Global Development, Washington DC.

Bornmann, Lutz, and Ruediger Mutz, 2014, "Growth Rates of Modern Science: A Bibliometric Analysis based on the Number of Publications and Cited References," Journal of the Association of Information Science and Technology 66: 2215-2222

Bothwell, Laura, Jeremy Greene, Scott Podolsky, and David Jones, 2016, “Assessing the Gold Standard-Lessons from the History of RCTs," New England Journal of Medicine 374(22): 2175-2181.

Brodeur, Abel, Mathias Lé, Marc Sangnier, and Yanos Zylberberg, 2016, "Star Wars: The Empirics Strike Back," American Economic Journal: Applied Economics 8(1):1-32.

Brown, Caitlin, Martin Ravallion and Dominique van de Walle, 2018, "A Poor Means Test? Econometric Targeting in Africa," Journal of Development Economics 134: 109-124.

Bruhn, Miriam, and David McKenzie, 2009, "In Pursuit of Balance: Randomization in Practice in Development Field Experiments," American Economic Journal: Applied Economics 1(4): 200-232.

Burtles, Gary, 1995, "The Case for Randomized Field Trials in Economic and Policy Research," Journal of Economic Perspectives 9(2): 63-84.

Chabé-Ferret, Sylvain, 2018, "An Approach Combining Theory, Simulations and Empirics Provides Evidence of Regularities in the Bias of Observational Methods," Toulouse School of Economics.

Cameron, Drew B., Anjini Mishra, and Annette N. Brown, 2016, "The Growth of Impact Evaluation for International Development: How Much Have We Learned?" Journal of Development Effectiveness 8 (1): 1-21.

Camerer, C. F., A. Dreber, E. Forsell, T.-H. Ho, J. Huber, M. Johannesson, M. Kirchler, J. Almenberg, A. Altmejd, and T. Chan, 2016, "Evaluating Replicability of Laboratory Experiments in Economics," Science 351(6280):1433-1436.

Card, David, and Stefano DellaVigna, 2013, "Nine Facts about Top Journals in Economics," NBER Working Paper 18665.

Cartwright, Nancy, 2007, “Are RCTs the Gold Standard?” BioSocieties 2(1): 11-20.

Chassang, Sylvain, Gerard Padró i Miquel and Erik Snowberg, 2012, "Selective Trials: A Principal-Agent Approach to Randomized Controlled Experiments," American Economic Review 102(4): 1279-1309.

Chen, Shaohua, Ren Mu and Martin Ravallion, 2009, “Are There Lasting Impacts of Aid to Poor Areas? Evidence from Rural China," Journal of Public Economics 93: 512-528.

Christensen, Garret, and Edward Miguel, 2018, “Transparency, Reproducibility, and the Credibility of Economics Research," Journal of Economic Literature 56(3): 920-980.

Cox, D.R., and N. Reid, (2000) The Theory of the Design of Experiments, Monographs on Statistics and Applied Probability 86, Chapman and Hall, New York.

Deaton, Angus, 2010, "Instruments, Randomization, and Learning about Development," Journal of Economic Literature 48(2): 424-455.

Deaton, Angus, and Nancy Cartwright, 2018, "Understanding and Misunderstanding Randomized Controlled Trials," Social Science and Medicine 210: 2-21.

Donovan, Kevin, 2018, "The Rise of the Randomistas: On the Experimental Turn in International Aid," Economy and Society 47(1): 27-58. 
Duflo, Esther, 2017, “The Economist as Plumber,” American Economic Review: Papers and Proceedings 107(5): 1-26.

Duflo, Esther, Pascaline Dupas, and Michael Kremer, 2015, “School Governance, Teacher Incentives, and Pupil-Teacher Ratios: Experimental Evidence from Kenyan Primary Schools," Journal of Public Economics 123: 92-110.

Duflo, Esther, Rachel Glennerster, and Michael Kremer, 2011, "Using Randomization in Development Economics Research: A Toolkit," in Handbook of Development Economics, Volume 4, Amsterdam: North-Holland.

Favereau, Judith, 2016, "On the Analogy between Field Experiments in Economics and Clinical Trials in Medicine," Journal of Economic Methodology 23(2): 203-222.

Fiennes, Caroline, 2018, "Funders Start Assessing Their Own Performance. To Understand What a Charity is Achieving, You Must Understand What Good Research Looks Like." Financial Times, November 27.

Finkelstein, Amy, and Sarah Taubman, 2015, "Randomize Evaluations to Improve Health Care Delivery," Science 347(6223): 720-722.

Fiszbein, Ariel, and Norbert Schady, 2010, Conditional Cash Transfers for Attacking Present and Future Poverty, World Bank, Washington DC.

Food and Drug Administration, 2010, Adaptive Design Clinical Trials for Drugs and Biologics, Food and Drug Administration, US Government. Washington DC.

Franco, Annie, Neil Malhotra, and Gabor Simonovits, 2014, "Publication Bias in the Social Sciences: Unlocking the File Drawer," Science 345(6203): 1502-1505.

Freedman, Benjamin, 1987. "Equipoise and the Ethics of Clinical Research," The New England Journal of Medicine 317(3):141-145.

Frieden, Thomas, 2017, "Evidence for Health Decision Making-Beyond Randomized Controlled Trials," New England Journal of Medicine 377(5): 465-475.

Friedman, Jed, and Brindal Gokul, 2014, "Quantifying the Hawthorne Effect," Development Impact Blog, World Bank.

Galasso, Emanuela, and Martin Ravallion, 2005, "Decentralized Targeting of an AntiPoverty Program," Journal of Public Economics 89(4): 705-727.

Galasso, Emanuela, Martin Ravallion, and Agustin Salvia, 2004, "Assisting the Transition from Workfare to Work: Argentina's Proempleo Experiment," Industrial and Labor Relations Review 57(5): 128-142.

Gertler, P. J., S. Martinez, P. Premand, L. Rawlings, and C.M.J. Vermeersch, 2016, Impact Evaluation in Practice (2nd edition), Washington, DC: Inter-American Development Bank and World Bank.

Glennerster, Rachel, and Shawn Powers, 2016, "Balancing Risk and Benefit. Ethical Tradeoffs in Running Randomized Evaluations," in George DeMartino and Deirdre McCloskey (eds) Oxford Handbook on Professional Economic Ethics, Oxford: Oxford University Press.

Glynn, Adam, and Konstantin Kashin, 2018, "Front-door Versus Back-door Adjustment with Unmeasured Confounding: Bias Formulas for Front-door and Hybrid Adjustments with Application to a Job Training Program," Journal of the American Statistical Association, forthcoming.

Goldberg, Jessica, 2014, “The R-Word Is Not Dirty,” Blog Post, Center for Global Development, Washington DC. 
Green, William, 1991, Econometric Analysis. New York : Macmillan.

Grossman, Jason, and Fiona Mackenzie, 2005, "The Randomized Controlled Trial: Gold Standard, or Merely Standard?” Perspectives in Biology and Medicine 48(4): 516-534.

Hahn, Jinyong, Petra Todd and Wilbert Van der Klaauw, 2001, "Identification and Estimation of Treatment Effects with a Regression-Discontinutiy Design," Econometrica 69(1): 201-209.

Hammer, Jeffrey, 2017, "Randomized Control Trials for Development? Three Problems," Brookings Institution Blog Post, May 11.

Hannan, Edward, 2008, "Randomized Clinical Trials and Observational Studies: Guidelines for Assessing Respective Strengths and Limitations," LACC: Cardiovascular Interventions 2(3): 211-217.

Heckman James, 1992, "Randomization and Social Policy Evaluation," in C. Manski and I. Garfinkel (eds), Evaluating Welfare and Training Programs, Cambridge, MA: Harvard University Press.

Heckman James and Jeffrey Smith, 1995, “Assessing the Case for Social Experiments," Journal of Economic Perspectives 9(2): 85-110.

Heckman, James, and Sergio Urzúa, 2010, "Comparing IV with Structural Models: What Simple IV Can and Cannot Identify," Journal of Econometrics 156: 27-37.

Heckman James, Sergio Urzua and Edward Vytlacil, 2006, "Understanding Instrumental Variables in Models with Essential Heterogeneity," Review of Economics and Statistics 88(3): 389-432.

Heckman, James, and Edward Vytlacil, 2005, "Structural Equations, Treatment Effects, and Econometric Policy Evaluation,” Econometrica 73(3): 669-738. , and _ 2007, "Econometric Evaluation of Social

Programs, Part I: Causal Models, Structural Models and Econometric Policy

Evaluation." In J.J. Heckman and E. Leamer (eds.). Handbook of Econometrics Volume 6B. Amsterdam: Elsevier.

Hernán Miguel A, and Jamie M. Robins, 2018, Causal Inference. Boca Raton: Chapman \& Hall/CRC, forthcoming.

Hinkelmann, Klaus, and Oscar Kemthorne, 2008, Design and Analysis of Experiments, New York: John Wiley.

Imbens, Guido, 2010, "Better LATE Than Nothing: Some Comments on Deaton (2009) and Heckman and Urzua (2009)," Journal of Economic Literature 48(2): 399-423. , 2018, "Comments on Understanding and Misunderstanding Randomized Controlled Trials: A Commentary on Deaton and Cartwright," Social Science and Medicine 210: $50-52$.

Ioannidis, John, 2005, "Why Most Published Research Findings are False," PLoS Medicine 2(8): 1-6.

Jamison, Dean, Barbara Searle, Klaus Galda, and Stephen P. Heyneman, 1981, "Improving Elementary Mathematics Education in Nicaragua: An Experimental Study of the Impact of Textbooks and Radio on Achievement," Journal of Educational Psychology 73(4): 556-567.

Kapur, Davesh, 2018, "Academic Research on India in the US: For Whom does the Bell Toll?" India in Transition, Center for the Advanced Study of India, University of Pennsylvania, June 29. 
Kasy, Maximilian, 2016, "Why Experimenters might not Always want to Randomize, and what they should do Instead," Political Analysis 24: 324-338.

Keane, Michael, 2010, "Structural vs. Atheoretic Approaches to Econometrics," Journal of Econometrics 156(1): 3-20.

Keating, Joshua, 2014, "Random Acts. What Happens when you Approach Global Poverty as a Science Experiment?" Slate, March 26.

Lancet, The, 2004, “The World Bank is Finally Embracing Science," The Lancet 364: 731-732.

Laura and John Arnold Foundation, 2018, "Request for Proposals: Randomized Controlled Trials to Evaluate Social Programs Whose Delivery Will Be Funded by Government or Other Entities," Laura and John Arnold Foundation.

Legovini, Arianna, Vincenzo Di Maro, and Caio Piza, 2015, "Impact Evaluation Helps Deliver Development Projects," Policy Research Working Paper 7157, World Bank.

Leigh, Andrew, 2018, Randomistas. How Radical Researchers Changed our World. New Haven: Yale University Press.

List, John A., and Imran Rasul, 2011, "Field Experiments in Labor Economics," in Handbook of Labor Economics, Volume 4, Part A, pp.103-228.

McKenzie, David, 2013, "How Should we Understand 'Clinical Equipoise' When Doing RCTs in Development?" Development Impact Blog, World Bank. 2019, "Discussant's Comments," in Kaushik Basu, David Rosenblatt and Claudia Paz Sepulveda (eds), State of Economics, State of the World, MIT Press, forthcoming. Meager, Rachael, 2018, "Understanding the Average Impact of Microcredit Expansion: A Bayesian Hierarchical Analysis of Seven Randomized Experiments," American Economic Journal: Applied forthcoming.

Moffitt, Robert, 2004, "The Role of Randomized Field Trials in Social Science Research," American Behavioral Scientist 47(5): 506-540.

2006, "Forecasting the Effects of Scaling Up Social Programs: An

Economics Perspective." In Barbara Schneider and Sarah-Kathryn McDonald, eds, ScaleUp in Education: Ideas in Principle. Rowman and Littlefield.

Morgan, Kari Lock, and Donald B. Rubin, 2012, "Rerandomization To Improve Covariate Balance In Experiments," Annals of Statistics 40( 2): 1263-1282.

Mulligan, Casey, 2014, “The Economics of Randomized Experiments," Economix Blog, New York Times, March 5.

Mummolo, Jonathan, and Erik Peterson, 2018, "Demand Effects in Survey Experiments: An Empirical Assessment," American Political Science Review, forthcoming.

Murgai, Rinku, Martin Ravallion and Dominique van de Walle, 2015, "Is Workfare Cost Effective against Poverty in a Poor Labor-Surplus Economy?", World Bank Economic Review 30(3): 413-445.

Narita, Yusuke, 2018, "Toward an Ethical Experiment," Cowles Foundation Discussion Paper No. 2127, Yale University.

Özler, Berk, 2018, “Incorporating Participants Welfare and Ethics into RCTs," Development Impact Blog Post, World Bank.

Pearl, Judea, 2009, Causality: Models, Reasoning and Inference (2nd edition). New York: Cambridge University Press.

Pearl, Judea, and Dana Mackenzie, 2018, The Book of Why. The New Science of Cause and Effect. New York: Basic Books. 
Peters, Jörg, Jörg Langbein and Gareth Roberts, 2018, "Generalization in the Tropics Development Policy, Randomized Controlled Trials, and External Validity," World Bank Research Observer 33(1): 34-64.

Pritchett, Lant, 2018, “The Debate about RCTs in Development is Over: We Won. They Lost." Presentation at the Development Research Institute, New York University. Pritchett, Lant, and Justin Sandefur, 2015, "Learning from Experiments when Context Matters," American Economic Review: Papers and Proceedings 105(5): 471-475.

Ravallion, Martin, 2009a, "Should the Randomistas Rule?" Economists' Voice 6(2): 1-5. ,2009b, "Evaluation in the Practice of Development," World Bank Research

Observer 24(1): 29-54.

2012, "Fighting Poverty one Experiment at a Time: A Review Essay on Abhijit Banerjee and Esther Duflo, Poor Economics," Journal of Economic Literature 50(1): 103-114. 2014, "On the Implications of Essential Heterogeneity for Estimating Causal Impacts Using Social Experiments," Journal of Econometric Methods 4(1): 145-151. ,2016, The Economics of Poverty: History, Measurement and Policy. New York:

Oxford University Press.

Ravallion, Martin, Dominique van de Walle, Puja Dutta, and Rinku Murgai, 2015, "Empowering Poor People through Public Information? Lessons from a Movie in Rural India," Journal of Public Economics 132(December): 13-22.

Rodrik, Dani, 2009, "The New Development Economics: We Shall Experiment, but How Shall We Learn?” In What Works in Development? Thinking Big and Thinking Small, ed. Jessica Cohen and William Easterly (Washington, D.C.: Brookings Institution Press).

Rosenbaum, Paul, and Donald Rubin, 1983, "The Central Role of the Propensity Score in Observational Studies for Causal Effects," Biometrika 70: 41-55.

Rutter, Harry, Natalie Savona, Ketevan Glonti, Jo Bibby, Steven Cummins, Diane Finegood, Felix Greaves, Felix, Laura Harper, Penelope Hawe, Laurence Moore, Mark Petticrew, Eva Rehfuess, Alan Shiell, James Thomas, and Martin White, 2017, “The Need for a Complex Systems Model of Evidence for Public Health,” Lancet 390(10112): 2602-04. Sabet, Shayda Mae, and Annette Brown, 2018, "Is Impact Evaluation Still on the Rise? The New Trends 2010-2015," Journal of Development Effectiveness 10(3): 291-304.

Silverman, Stuart, 2009, "From Randomized Controlled Trials to Observational Studies," American Journal of Medicine 122(2): 114-120.

Skoufias, Emmanuel, and Susan Parker, 2001, "Conditional Cash Transfers and Their Impact on Child Work and Schooling: Evidence from the PROGRESA Program in Mexico," Economía 2(1): 45-86.

Tavernise, Sabrina, 2015, "Few Health System Studies use Top Method, Report Says," New York Times February 12.

Todd, Petra, and Kenneth Wolpin, 2006, “Assessing the Impact of a School Subsidy Program in Mexico using Experimental Data to Validate a Dynamic Behavioral Model of Child Schooling," American Economic Review 96(5): 1384-1417.

Vass, Mikkel, 2010, Prevention of Functional Decline in Older People: The Danish Randomised Intervention Trial on Preventative Home Visits. Doctoral Dissertation, Faculty of Health Science, University of Copenhagen, Copenhagen, Denmark. 
Vivalt, Eva, 2017, "How Much Can We Generalize from Impact Evaluations?” Australian National University.

Webber, Sophie, and Carolyn Prouse, 2018, “The New Gold Standard: The Rise of Randomized Control Trials and Experimental Development," Economic Geography 94(2): 166-187.

White, Howard, 2014, “Ten Things that can go Wrong with Randomised Controlled Trials," Evidence Matters Blog, International Initiative for Impact Evaluation.

World Bank, 2012, World Bank Group Impact Evaluations: Relevance and Effectiveness. Independent Evaluation Group, World Bank. , 2016, Transforming Development through Impact Evaluation. I2i DIME Annual Report, World Bank, Washington DC.

Wydick, Bruce, 2018, "Review of Randomistas: How Radical Researchers Changed Our World," Development Impact Blog, World Bank.

Young, Alwyn, 2018, "Hanneling Fisher: Randomization Tests and the Statistical Insignificance of Seemingly Significant Experimental Results," Quarterly Journal of Economics, forthcoming.

Ziliak, Stephen T., 2014, "Balanced versus Randomized Field Experiments in Economics: Why W. S. Gosset aka "Student” Matters," Review of Behavioral Economics 1: 167-208.

Ziliak, Stephen T. and Edward R. Teather-Posadas, 2016, “The Unprincipled Randomization Principle in Economics and Medicine," in George DeMartino and Deirdre McCloskey (eds) Oxford Handbook on Professional Economic Ethics, Oxford: Oxford University Press. 